San Jose State University

SJSU ScholarWorks

Master's Projects

Master's Theses and Graduate Research

Spring 2019

\title{
Exploring Civil Service Eligibility List De-Identification Practices Among Large U.S. Cities
}

Zayba Shaikh

San Jose State University

Follow this and additional works at: https://scholarworks.sjsu.edu/etd_projects

Part of the Other Public Affairs, Public Policy and Public Administration Commons, Policy Design, Analysis, and Evaluation Commons, and the Public Administration Commons

\section{Recommended Citation}

Shaikh, Zayba, "Exploring Civil Service Eligibility List De-Identification Practices Among Large U.S. Cities" (2019). Master's Projects. 669.

DOI: https://doi.org/10.31979/etd.k5gw-tztx

https://scholarworks.sjsu.edu/etd_projects/669

This Master's Project is brought to you for free and open access by the Master's Theses and Graduate Research at SJSU ScholarWorks. It has been accepted for inclusion in Master's Projects by an authorized administrator of SJSU ScholarWorks. For more information, please contact scholarworks@sjsu.edu. 


\title{
Exploring Civil Service Eligibility List
}

\section{De-Identification Practices Among Large U.S. Cities}

\author{
by \\ Zayba Shaikh
}

A Thesis Quality Research Paper

Submitted in Partial Fulfillment of the

Requirements for the

Masters Degree

in

\section{PUBLIC ADMINISTRATION}

Professor Frances L. Edwards, Ph.D.

The Graduate School

San Jose State University

Spring 2019 
Table of Contents

List of Tables, Figures, and Appendix................................................. 5

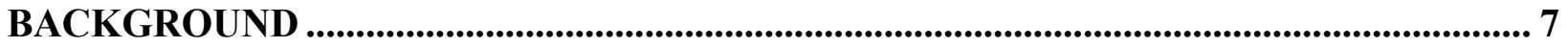

The Civil Service System ............................................................................................................ 7

The City and County of San Francisco: New Rule Reform ................................................ 9

The Federal Standard: Office of Personnel Management ................................................... 12

City Government Forms......................................................................................... 15

What is an Eligibility List \& How Does it Work? ..................................................... 17

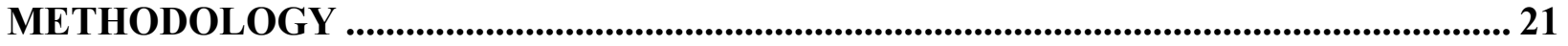

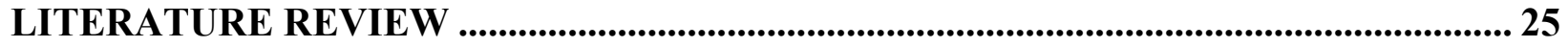

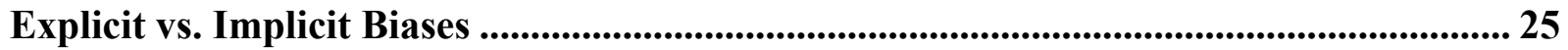

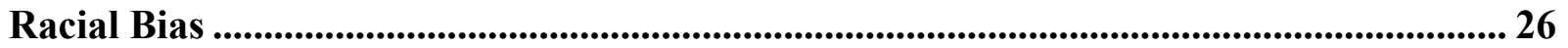

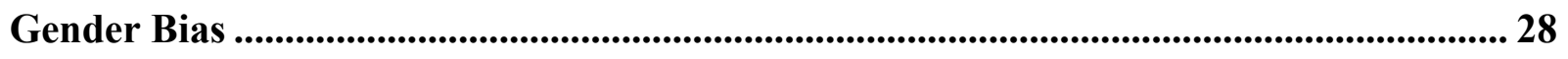

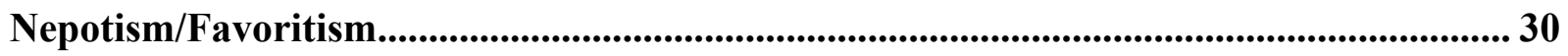

Privacy in Public Sector Hiring .................................................................................................... 31

Preventing Bias in Public Sector Hiring ............................................................................ 32

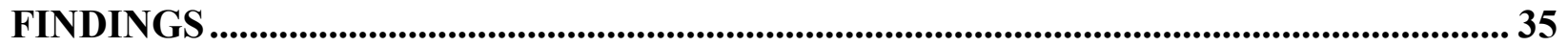

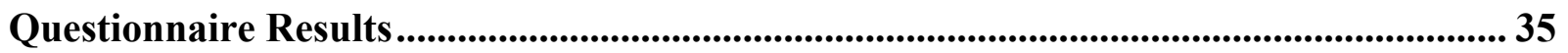

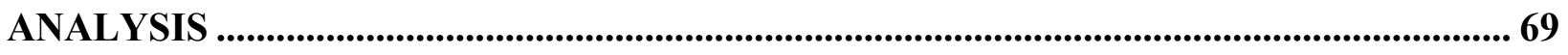

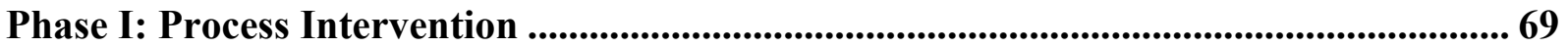

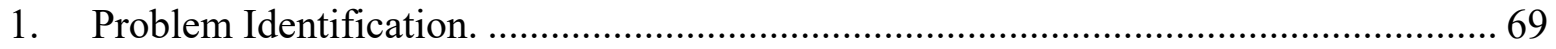

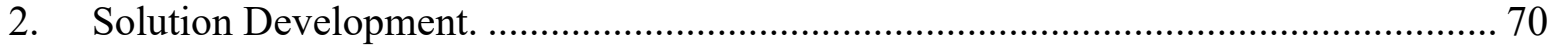

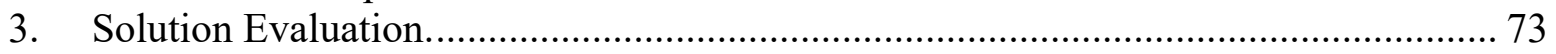

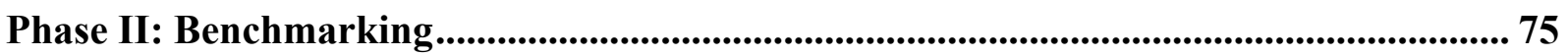

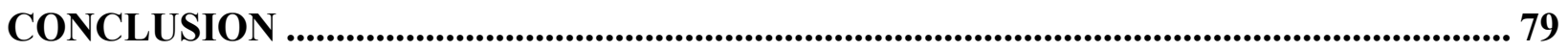

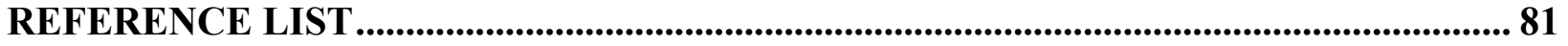

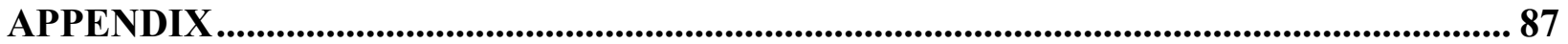




\section{List of Tables, Figures, and Appendix}

\section{TABLES}

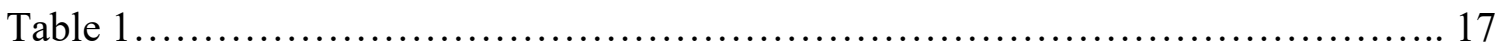

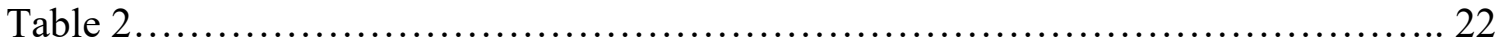

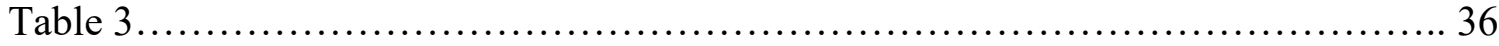

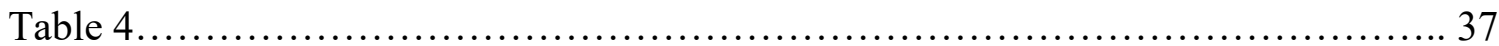

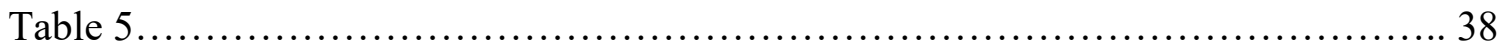

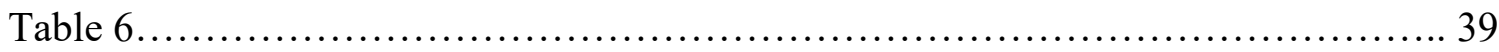

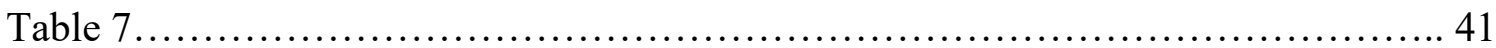

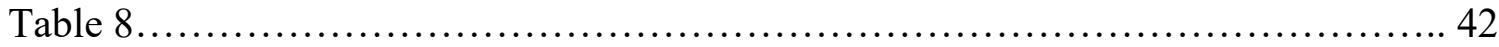

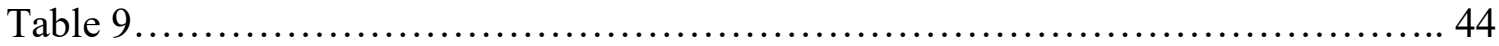

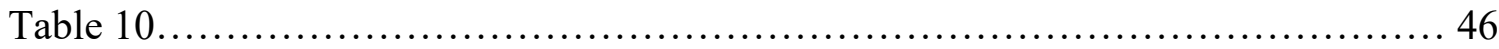

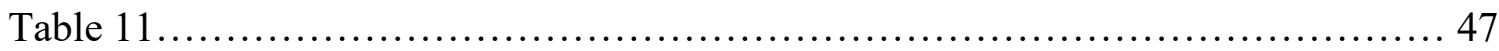

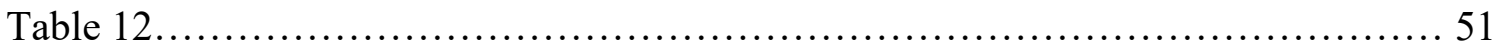

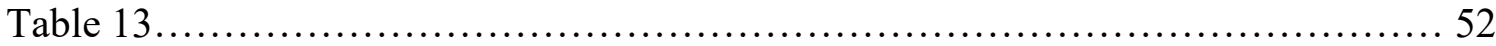

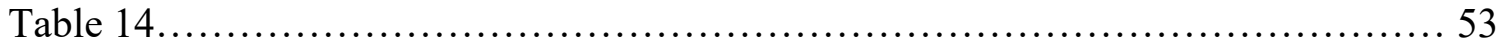

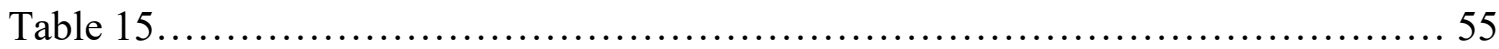

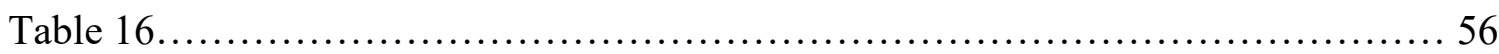

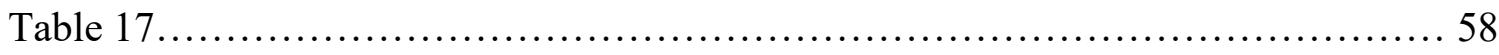

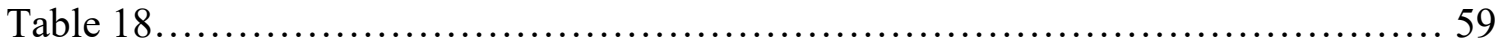

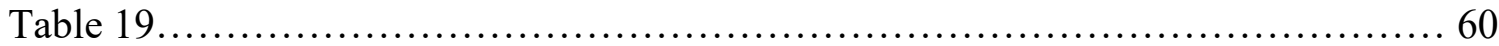

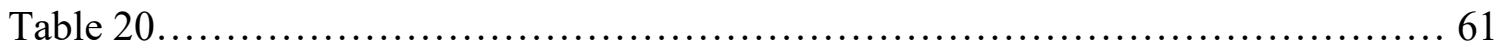

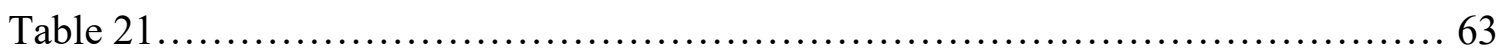

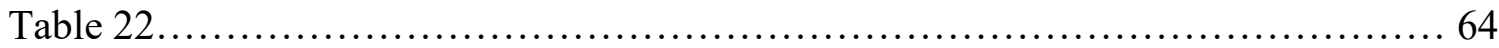

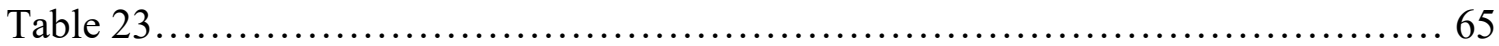

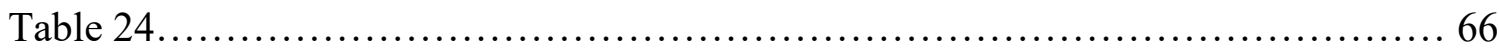

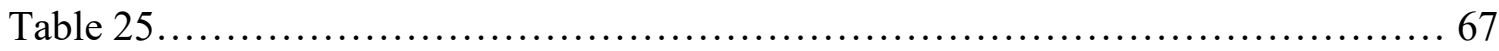

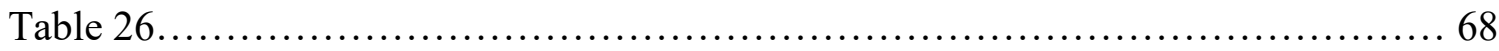

\section{FIGURES}

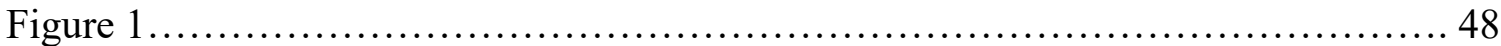

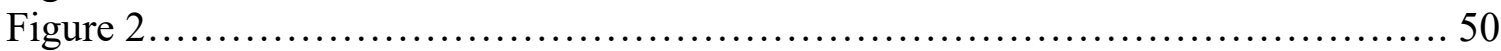

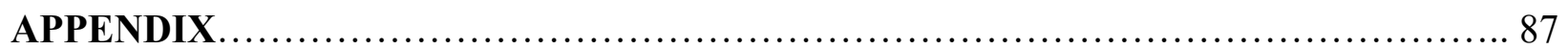





\section{The Civil Service System}

\section{BACKGROUND}

Civil service in the United States refers to a system of hiring staff for government positions (McKay, 2018). At the federal level, the civil service system was created in the 1880's to end the system of patronage appointments, where people were appointed to government jobs based on their political activity in the newly elected president's political campaign. States and local governments then adopted the system (Chieppo, 2013).

The civil service system was based on apolitical tests that would gauge the relative knowledge, skills and abilities of the applicants, with the goal of hiring people who best fit the demands of the position, regardless of political attributes (Rosenbloom, Kravchuk, \& Clerkin, 2014). Civil service testing resulted in scores that were recorded in a list of qualified candidates, ranked in order of their skills as demonstrated through the testing process and reflected in the numerical score; the first name on the list represented the person with the highest test score (Chieppo, 2013).

Over time governing bodies in many organizations have determined to embed social justice concepts into the testing system (Rosenbloom, Kravchuk, \& Clerkin, 2014). For example, for some positions the federal government adds points to a person's score based on veteran's status (Chieppo, 2013). Some communities create "bands" to segregate applicants by race, to ensure that the most qualified candidate from each racial group, or disadvantage racial group, or underrepresented racial group is hired, to enhance diversity within the organization's employees (Chieppo, 2013). The rules for collecting and using such information are based on federal equal opportunity and affirmative action laws (U.S. Department of Labor, 2019). For example, Executive Order 11246 ("EEO and Affirmative Action Guidelines for Federal Contractors Regarding Race, Color, Gender, Religion, and National Origin") is an example of a law that has 
been put in place to remedy historic discrimination (Electronic Code of Federal Regulations, 2019). Massachusetts has created a system of "preferences" that modifies an applicant's score based on various relationships to public safety or veterans (Chieppo, 2013). Individuals wishing to claim the preferences of extra points will have to disclose personal information that might otherwise be illegal to collect, such as veteran's status (Chieppo, 2013).

However, there are many categories of information that may not be legally collected in the hiring process outside of an affirmative action program. These include age, race, gender, sexual orientation, marital status and other personal and non-job-related data (Giang, 2013). More recently the hiring process has been modified to include evaluation methods other than paper and pencil testing, since concerns were raised about pencil and paper tests being inherently discriminatory (McKay, 2018).

Prior to October 15, 2018, the City and County of San Francisco (CCSF) created all of its hiring eligibility lists with full personal identification for each candidate (Callahan, 2018). These lists were posted and were publicly available on the city's website, and as hard copies at the Department of Human Resources office (City and County of San Francisco Department of Human Resources, 2018). The lists featured an eligible candidate's last name, first name, middle initial, examination score, and rank (City and County of San Francisco Department of Human Resources, 2018). With this identifying information available to all persons included in every facet of the hiring process, issues of candidate confidentiality, bias, nepotism, and conflicts of interest arose and became the impetus for civil service rule reform for CCSF (Callahan, 2018). One facet of the reform was the elimination of some personally identifying information from the published lists. This is known as de-identification. 
Publishing or otherwise making public a civil service list with personally identifying information creates many undesirable outcomes for applicants. A low score on the test may cause embarrassment. Appearing on a hiring list may create problems at the applicant's current job. The person's name, revealing in many cases gender and ethnicity, may create the basis for discrimination within the hiring process.

The intention of this study is to explore how de-identification practices for Civil Service eligibility lists (removing personally identifiable information from the hiring list) differ among large U.S. cities that compose of San Francisco's market. Areas of focus within this study include an analysis of current and past eligibility list creation processes in market cities, as well as the examination of methods used by CCSF and the market cities when using eligibility lists for hiring purposes. The methods and processes that the market cities use, which are covered in the Findings section, were compared to each other's to allow for benchmarking. An examination of the best practices of the market cities may result in improvement of CCSF's hiring processes.

\section{The City and County of San Francisco: New Rule Reform}

Minimizing negative externalities, such as bias and nepotism, has been found to promote diversity (Goldin \& Rouse, 1997). A long-stated goal of CCSF has been to reduce discrimination such as nepotism in their hiring processes (Callahan, 2018). This has led the CCSF to propose a civil service rule reform directly impacting the formation of their eligibility lists (Callahan, 2018). A new de-identified process for creating eligibility lists and sharing them in the postreferral selection process went into effect on October 15, 2018 (City and County of San Francisco: Civil Service Commission, 2018).

Previously, CCSF publicly posted eligibility lists of applicants who passed the civil examination. This list included personally identifying information such as full names, scores and 
ranks. These lists were made available on the CCSF Human Resources website, which meant that anyone had access - including hiring managers and those involved in the hiring process. In addition to the publicly posted eligibility lists, applications and supplemental documents, including applicant addresses, phone numbers, names of educational institutions, and employer names, provided the hiring department with information that could raise judgements about an applicant when race, ethnicity, gender, age, and nationality are publicly available (Callahan, 2018).

CCSF acknowledged that nepotism and favoritism may be underlying problems in their hiring process. In December 2016, a memorandum was sent by the Civil Service Commission to all city employees, reminding them that the city must maintain " $[\ldots]$ a professional work environment free of conflicts of interests, nepotism, and favoritism" to ensure that CCSF follows the merit-based employment process (Civil Service Commission City and County of San Francisco, 2016). The Civil Service Commission wrote the memorandum to acknowledge the multiple complaints of favoritism and nepotism in employment-related situations that were expressed to them (Civil Service Commission City and County of San Francisco, 2016). The memorandum highlights the city's Conduct of Government Code 3.212-3.214 that clearly states that employment decisions based on nepotism and favoritism cannot be made, and legal penalties can be incurred for hiring situations that have used nepotism and favoritism (San Francisco Campaign and Governmental Conduct Code, 2018). A reminder memorandum was published shortly afterward in February 2017, highlighting the same issues (Civil Service Commission City and County of San Francisco, 2017).

The public posting of eligibility lists presents additional issues. First, candidates may be unwilling to take an examination if fully identified scores will be published, leading to 
embarrassment if their scores are low. Publicized personal information can cause emotional distress, affecting the employee's morale at work and leading to lower productivity (Shattuck, 1989). Published identified scores can also affect how colleagues perceive their co-workers' knowledge and skills to do the current job, or to receive a promotion (Shattuck, 1989).

The second concern is regarding an individual's choice of pursuing other employment. A candidate may not want his or her current employer to know that he or she is looking for a new job. In the state of California, "at-will" employment is legal, meaning that the employee or employer can terminate employment at any time (McDonald, 2017). At will employees might fear that disclosure of the employee's status as a candidate for another job could jeopardize the current job. This could be considered a breach of privacy that a public employee might face. Deidentification measures help maintain an individual's privacy by eliminating details from eligibility lists that could disclose the job search to a current employer. The third concern is about the constitutional privacy rights of public employees. Per Division 3 of California Government Labor Code, all employees in California benefit from protective employment laws (California Legislative Information, 2019). Under the California Fair Employment and Housing Act (FEHA), public and private employers are prohibited from illegally discriminating against an employee based on a protected category in the terms and conditions of employment (California Department of Fair Employment and Housing, 2019). This protects employees the areas of race, religion, color, national origin and ancestry, physical or mental disability, medical condition, genetic information, marital status, sex, sexual orientation, gender identity/gender expression, pregnancy, age, and military/ veteran status.

Public employees can expect all of their work, and most job-related personal information, to be readily available to the public (Roberts \& Doss, 1991) On the job, an employer is "[...] 
generally allowed to monitor [an employee's] workplace communications such as business phone calls and computer usage, and to access to voicemail and e-mail" (State of California, Department of Justice, 2019). Additionally, an employee's individual personnel matters are protected, but salaries, which are part of the public agency budget, are not. Thus, the question of “to what extent are privacy rights afforded to public employees?" is raised. Some of a public employee's personally identifying information can be publicly available during the hiring process and this is perfectly legal, if kept within the bounds of federal and state laws. But it is important to note that this information being available might prejudice the hiring process. What purpose does this information serve in a civil service merit-based hiring system?

CCSF wishes to avoid occurrences of nepotism and favoritism in its hiring practices. Nevertheless, allegations of nepotism and favoritism have been lodged by current employees and applicants. Although CCSF has rules and policies in place to combat these practices, the subconscious biases of those individuals involved in hiring decisions cannot be controlled (Callahan, 2018). Personal identification such as names can reveal gender and possibly ethnicity, which might endanger unconscious bias in the reviewer. Thus, de-identification measures should be implemented in a merit-based hiring process to try to curb nepotism and subconscious biases (ultimately a form of discrimination) that conduct codes and policies alone cannot control. This ensures the use of fair hiring practices. De-identification measures can serve this purpose by limiting information that could lead to unfair hiring practices.

\section{The Federal Standard: Office of Personnel Management}

The United States Office of Personnel Management (OPM) is the federal agency equivalent to a city's local Department of Human Resources. The way OPM handles its hiring decisions is 
significant because their hiring processes must pass the standards set by the Office of Equal Opportunity.

The evaluation of applications is done by the Human Resources Office (HRO) at the OPM. This process takes approximately 15 days, and HRO employees "evaluate, rate, and rank the applications received and notify the applicants of the results of their qualification review" (Office of Personnel Management, 2019, n.p). All applications are reviewed and evaluated based on the minimum qualifications listed in the job announcement, selective placement factors (competencies or tasks determined by a formal job analysis), and quality ranking factors (knowledge, skills, and abilities determined by a formal job analysis) (Office of Personnel Management, 2019). Next, “[...] all applications are reviewed for legal requirements such as veterans' preference, citizenship, and age. HRO will also screen the applications for suitability for the position $[\ldots]$ to determine that the applicant meets the risk level designation and/or sensitivity level/clearance eligibility for the position" (Office of Personnel Management, 2019, n.p). Then, HRO “[...] will rate and rank applications based on the assessment tool created for the position; apply veterans' preference, if appropriate; and place the eligibles in the appropriate ranking order" (Office of Personnel Management, 2019, n.p). Previously, OPM used a numerical ranking process, known as the "Rule of Three", which limited hiring consideration to the top three scoring candidates (Neal, 2014). Certain veterans who received passing scores were given preference in the form of additional ranking "points" (Office of Personnel Management, 2019). This ranged from an additional five to ten extra points added to the eligible veteran's numerical rating (Office of Personnel Management, 2019). For example, "[...] a disabled veteran who earns a score of 100 has 10 extra points added" (Office of Personnel Management, 2019, n.p). Due to these additional points, veterans commonly were in the top three ranked positions (Neal, 2014). 
In 2018, the Rule of Three was overturned and agencies were granted more flexibility in making hiring considerations, as they were no longer restricted to the top three candidates (Fedweek, 2018). It is unclear what certification rule(s) OPM currently uses to select which candidates to interview.

Next, all candidates are then placed on the eligibility lists, in the order of their rankings (Office of Personnel Management, 2019). Lastly, the eligibility list is shared with departments that need to fill the vacant positions, and "Competitor inventories are established from which selections will be made over a period of time and for case examining in which a register is used to fill a single position or a group of positions and is closed after the needed selection(s) is made" (Office of Personnel Management, 2019, n.p).

The next step is for the HRO to compile their equivalent of an eligibility list, known as the Issue of Certificate and Notify Eligibles. In this step, HRO

[...] issues a certificate of eligibles to the selecting official. The HRO creates this certificate by rank ordering the eligible candidates based on the ranking procedure identified in the job opportunity announcement and eligible candidates identified in the fourth step of the Evaluate Applications element. After the certificate is issued to the selecting official, the HRO will notify applicants of the status of their applications, i.e. whether they were determined eligible or ineligible for the position (Office of Personnel Management, 2019, n.p).

It is unclear on the OPM website how HRO informs applicants on their rankings (online, e-mail, phone call, or letter) and what information (personally identifying information or general candidate information) is included on the certificate of eligibles provided to the selecting officials. 
The last step in the OPM hiring process is performed by the hiring manager filling the vacant position. This step consists of reviewing applications of eligible candidates, scheduling and conducting interviews, checking references, and making a selection (Office of Personnel Management, 2019). During this step, the manager

[...] reviews applications of eligible candidates on the certificate issued by HRO. When doing this, the manager determines the best eligible candidate for the position based on a review of the applications/resumes and all appropriate documents. Next the manager schedules and conducts interviews. When scheduling and conducting interviews the manager needs to remember to: Determine and follow agency policy on interviewing eligibles [...] (Office of Personnel Management, 2019, n.p).

The standards set by the Office of Equal Opportunity are the nationally used practice, and the hiring processes of the cities selected for this study can be compared to OPM; and comparisons will be illustrated in the applicable tables in the Findings section.

\section{City Government Forms}

All cities have a form for their government organization, based on a city charter, state laws or local selection. According to the National League of Cities (2019), the three most common forms of local government management in the United States are Council-Manager, Mayor-Council, and Commission. The cities selected for this study either use the CouncilManager or Mayor-Council form of government management.

Council-Manager form is the most popular and is most common in cities with a population size of over 10,000. In a Council-Manager government, there is an elected governing body, the "council", that is responsible for the legislative functions of the city. Additionally, a professional manager is appointed by the council to oversee the administrative functions of the 
city. In a Council-Manager government, the mayor is usually a ceremonial title and is assigned executive functions by the council (National League of Cities, 2019). The Council-Manager form of government was initially implemented to rid city governments of political management, which caused issues such as nepotism and favoritism in the hiring of government employees (ICMA, 2018). A Council-Manager form of government helps reduce the application of political power in the management of a city.

Mayor-Council form is the second most common form of government management. It differs from Council-Manager because the mayor is separately elected from the council and given significant administrative and budgetary authority (National League of Cities, 2019). Depending on the city charter, the mayor can possess weak or strong powers (also known as "Strong-Mayor" or "Weak-Mayor" forms). The cities with the mayor-council organizations selected for this study are all Strong-Mayor forms. This essentially means that the mayor has the ability to make independent administrative and executive decisions, which can also include hiring decisions. With cities that manage by a Strong-Mayor form, issues such as nepotism and favoritism are common (ICMA, 2008). This is why it is important for cities to understand the rules and policies outlined by appointing authorities to avoid hiring decisions based on political management when the law requires a civil service process.

Table 1 illustrates the cities selected for this study, their population sizes, and government form of each city. 
Table 1:

\begin{tabular}{|l|c|c|c|}
\hline \multicolumn{1}{|l|}{ Government Organization } & Population Size & $\begin{array}{c}\text { Council- } \\
\text { Manager }\end{array}$ & $\begin{array}{c}\text { Strong- } \\
\text { Mayor }\end{array}$ \\
\hline \multicolumn{3}{|l|}{} & $\mathbf{X}$ \\
\hline $\begin{array}{l}\text { Commonwealth of Massachusetts } \\
\text { (Boston, MA) }\end{array}$ & $\mathbf{6 , 9 0 2 , 1 4 9}$ & & \\
\hline San Jose, CA & $\mathbf{1 , 0 3 5 , 3 1 7}$ & $\mathbf{X}$ & $\mathbf{X}$ \\
\hline Austin, TX & $\mathbf{9 5 0 , 7 1 5}$ & $\mathbf{X}$ & $\mathbf{X}$ \\
\hline Jacksonville, FL & $\mathbf{8 9 2 , 0 6 2}$ & & $\mathbf{X}$ \\
\hline $\begin{array}{l}\text { San Francisco, CA } \\
\text { (consolidated city and county) }\end{array}$ & $\mathbf{8 8 4 , 3 6 3}$ & & $\mathbf{X}$ \\
\hline Charlotte, NC & $\mathbf{8 5 9 , 0 3 5}$ & $\mathbf{X}$ & $\mathbf{X}$ \\
\hline Seattle, WA & $\mathbf{7 2 4 , 7 4 5}$ & & \\
\hline Detroit, MI & $\mathbf{7 1 3 , 7 7 7}$ & & \\
\hline $\begin{array}{l}\text { Denver, CO } \\
\text { (consolidated city and county) }\end{array}$ & $\mathbf{7 0 4 , 6 2 1}$ & & \\
\hline
\end{tabular}

\section{What is an Eligibility List \& How Does it Work?}

An eligibility list is an inventory of applicants who have applied for a specific job, taken a competitive examination (written, oral, or observational), and received a passing score (Government of Northwest Territories, 2018). These candidates are ranked on the basis of their scores, listed from the highest passing score to the lowest passing score (New York Citywide Administrative Services, 2018).

There are many forms of eligibility lists, and cities may use multiple types. Each eligibility list has a specified length of time (months or years) until it expires. The expiration date determines how long an eligibility list stays active in order to be used for hiring and recruiting purposes. Once an eligibility list expires, it can no longer be used to fill vacant positions, and an examination must be administered to create a new list. For example, CCSF uses two types of lists: 
- Discrete: “[...] open for filing for a specific time period and in which the selection procedure is administered on a specific date or dates" ("Rule 112 Eligible Lists", 2018, n.p). These are also known as "position-based" lists, as each list is specific to a position and/or a department within the city.

- Duration: The minimum duration is six months, and the maximum is twenty-four months (City and County of San Francisco: Civil Service Commission, 2018).

- Continuous: Also known as a "city-wide" list, this list is used for city-wide positions where vacancies occur frequently and " $[\ldots]$ the names of the eligibles resulting from the examination shall be added to the existing eligible list [...]" (City and County of San Francisco: Civil Service Commission, 2018, n.p).

- Duration: The minimum duration is six months, and the maximum duration is twelve months (City and County of San Francisco: Civil Service Commission, 2018).

In comparison, the City of Jacksonville has seven eligibility list types:

- Internal Recruitment Priority 1: "Eligibility lists of permanent employees in the promotionally-eligible class(es) within the City from which promotional appointments may be made" (City of Jacksonville, Florida, 2016, n.p).

- Duration: The duration is two years, unless extended or exhausted (City of Jacksonville, Florida, 2016).

- Internal Recruitment Priority 2: "Eligibility lists of City employees within the department who meet the open requirements and for positions in the JEA (electricity, water and sewer agency) only" (City of Jacksonville, Florida, 2016, n.p). 
○ Duration: The duration is ninety calendar days, unless extended or exhausted (City of Jacksonville, Florida, 2016).

- External Recruitment: "Eligibility lists which may be used for making original appointments" (City of Jacksonville, Florida, 2016, n.p).

- Duration: The duration is one year, unless extended or exhausted (City of Jacksonville, Florida, 2016).

- Layoff/Demotion: "Eligibility lists which shall be used for reinstatement appointments in the same class within the competitive area of former employees who were laid off or demoted" (City of Jacksonville, Florida, 2016, n.p).

- Duration: The duration is one year, unless extended or exhausted (City of Jacksonville, Florida, 2016).

- Priority Reemployment: "Eligibility lists of permanent employees who have separated or were reassigned due to disability and who are determined to be capable of returning to their former or lower level positions" (City of Jacksonville, Florida, 2016, n.p).

○ Duration: The duration is one year, unless extended or exhausted (City of Jacksonville, Florida, 2016).

- Layoff Reemployment: "Eligibility lists which may be used for reinstatement appointments to comparable or lower level classes citywide of former permanent employees who were laid off or demoted" (City of Jacksonville, Florida, 2016, n.p).

○ Duration: The duration is one year, unless extended or exhausted (City of Jacksonville, Florida, 2016). 
- Reemployment: "Eligibility lists of permanent employees who have resigned from Civil Service who request to be placed on lists for the class from which separated or lower level classes in the same class series" (City of Jacksonville, Florida, 2016, n.p).

○ Duration: The duration is not specified (City of Jacksonville, Florida, 2016). Since all candidates on an eligibility list have met the minimum qualifications and obtained a passing score, a hiring department can choose anyone from an eligibility list to hire or interview for vacancies (City and County of San Francisco: Department of Human Resources, 2018). However, this depends on the certification rule(s) established by the Civil Service Commission in each respective city. Each city varies in the type of certification rule it can use to fill its positions. Different recruitments will use different certification rules, and many types of certification rules exist (Schmitt \& Martin, 2018). For example, the City of Philadelphia uses the "Rule of Two" for all its vacancies (Schmitt \& Martin, 2018). A "Rule of Two" suggests that a hiring manager can choose candidates that have ranked top two on the eligibility list. The hiring manager can then hire or interview them for the vacancy based on the department's internal hiring processes (Schmitt \& Martin, 2018). In contrast, the City of Austin has an "all passing scores," certification rule that essentially allows anyone who has obtained a passing score a spot on the eligibility list; any candidate with a passing score can be selected for interviews, or be immediately hired (City of Austin, 2014). 


\section{METHODOLOGY}

The objective of this study was to determine the de-identification practices of eligibility lists among large U.S. cities that use a merit-based hiring process. Hiring practices of the City and County of San Francisco (CCSF) and other cities were collected and analyzed in this study. To evaluate this process change, this study used a two-phased research method and implemented methodologies from two sources: process intervention (Sylvia and Sylvia, 2004) and benchmarking (Bardach and Patashnik, 2015).

There are four steps in process intervention: problem identification, solution development, solution implementation, and evaluation (Sylvia \& Sylvia, 2004). Because CCSF's new de-identification rule has not yet been implemented long enough to collect meaningful implementation data, phase I of this study used the first three steps of the process intervention methodology (with a solution evaluation) in order to collect information about the deidentification process.

Phase II consisted of a benchmarking process that used a questionnaire to identify commonalities in the management of civil service eligibility lists among the selected cities surveyed (Sylvia \& Sylvia, 2004). This data was used to evaluate the de-identification process based on multiple city experiences which is presented in the analysis section of this study (Bardach \& Patashnik, 2015). It is anticipated that the two-fold approach to the analysis will suggest whether or not de-identification practices on eligibility lists is a proven best practice for cities that aim to conduct a merit-based hiring process.

Qualitative methods are the most appropriate way to find answers to the research question. The qualitative methods used for this paper came from data collected through the Literature Review, along with the answers collected from the questionnaire. The questionnaire is 
comprised of 20 multiple choice and short answer questions, which acquired information pertaining to how the selected cities use de-identification measures in their hiring processes. The questionnaire is shown in the Appendix. Qualtrics, an online survey platform, was used to administer the questionnaire. The questionnaire was distributed via an anonymous link by e-mail to Human Resources professionals of the city governments selected for this study. Follow-up was completed by e-mail correspondence. Cities were selected based on their proximity to San Francisco and population size when compared to San Francisco, based on data collected from the U.S. Census Bureau (2018). The results from the questionnaire are public information, and further data collected will be disclosed in the Findings section of this study. The cities surveyed for this analysis are indicated in Table 2 .

Table 2:

\begin{tabular}{|l|c|}
\hline \multicolumn{2}{|c|}{ Government Organization } \\
\hline Commonwealth of Massachusetts \\
\hline San Jose, CA & $\mathbf{6 , 9 0 2 , 1 4 9}$ \\
\hline Austin, TX & $\mathbf{1 , 0 3 5 , 3 1 7}$ \\
\hline Jacksonville, FL & $\mathbf{9 5 0 , 7 1 5}$ \\
\hline San Francisco, CA & $\mathbf{8 9 2 , 0 6 2}$ \\
\hline Charlotte, NC & $\mathbf{8 8 4 , 3 6 3}$ \\
\hline Seattle, WA & $\mathbf{8 5 9 , 0 3 5}$ \\
\hline Detroit, MI & $\mathbf{7 2 4 , 7 4 5}$ \\
\hline Denver, CO & $\mathbf{7 1 3 , 7 7 7}$ \\
\hline
\end{tabular}

The cities selected for this study are referred to as the "market." The term is defined as cities with similar population sizes and diverse demographics. They are compared against San Francisco to understand whether they use de-identification measures in the administration of the civil service eligibility lists in their hiring processes. The basis of choosing these cities as the market was to offer a variation in population size. The top four cities are greater in population 
size than San Francisco, and the remaining four cities are lesser in population size than San Francisco (U.S Census Bureau, 2018). San Francisco is the defined median for population size. The cities were also chosen due to their physical locations to ensure a variation of cities representing areas both east and west of the Mississippi River. Originally, the city of Boston was to be included as a market city. However, research revealed that the city of Boston is required to request any eligibility lists through the state-wide Civil Service Commission of Massachusetts. In order to include Boston in the market, the Commonwealth of Massachusetts will serve as a "market city" in lieu of the city of Boston. The geographic variety of the market cities allows for the study to take a comprehensive view of the effects of de-identifying within a merit-based hiring process.

This study does not analyze all factors about the market to make a definitive statement about the value of de-identifying eligibility lists for all cities in the U.S., because developing comparability measures is outside the scope of this study. The selection of the market included cities of comparable population sizes and varying locations. Factors like the organizations' budget, the numbers of people employed, and the ethnic make-up of the populations within the cities' boundaries were not collected. Due to the varying structural and process differences among the market cities, the goal of the research was not to present a perfect solution, but rather to provide a well-rounded analysis that may help CCSF and other cities understand the probable value of civil service eligibility list de-identification. 


\section{LITERATURE REVIEW}

In many jurisdictions that use a civil service system for hiring, once a civil service examination is completed, an eligibility list is created. A human resources department can establish a list of candidates who meet the minimum qualifications and have received passing scores. Hiring departments then use the list in order to hire and fill the vacant position(s) advertised. This supports the civil service process to hire through a meritocratic system, rather than permitting favoritism or nepotism (Sundell, 2014). This is the point in the hiring process that differs among cities and is a vital part in understanding how and why some cities publish eligibility lists the way they do.

Although the role of eligibility lists is to try to prevent negative externalities from entering the hiring process, issues such as racial bias, gender bias, nepotism, and favoritism are external conflicts of interest that have been proven to affect the hiring process in ways that negate a merit-based process (Jones, 2012). Understanding why some cities publicly post their eligibility lists with or without personally identifying information (or in various identified/de-identified versions) is crucial to discovering whether this process is the best practice for a merit-based system. Though there is no substantial research that specifically speaks to the accuracy and efficiency of eligibility lists in a merit-based process, there has been significant research done on different types of biases that are prevalent in various hiring situations, and their impacts on the public sector merit-based hiring processes.

\section{Explicit vs. Implicit Biases}

Bias is a natural human prejudice that results from the tendency and need for humans to classify individuals into categories in order to process information and make sense of the world (Ross, 2008). Regardless of how just or fair-minded an individual perceives himself to be, biases are 
prejudices every human being possesses (Moule, 2009). Biases allow humans to make automatic assumptions, whether negative or positive, about other people or groups of people based on cultural stereotypes, rather than careful considerations (Holroyd, Scaife, \& Stafford, 2017).

Biases can be explicit or implicit. An example of explicit bias is racist comments. Usually, the individual making racist comments is aware of his or her attitude towards the person and/or group (Moule, 2009). An implicit bias is more discreet and is active in an individual's subconscious. The individual's feelings, stereotypes, and attitudes towards a person or group influences their preferences - negative or positive (Tetlock \& Mitchell, 2009). Unfortunately, explicit and implicit biases are present in all workplaces because all employees bring with them preferences, stereotypes, and feelings to the workplace on a daily basis (McCormack, 2016). Because it is a natural human trait, it is quite difficult to control in professional settings (McCormack, 2016). This is why it becomes so important for public sector workplaces to acknowledge and manage these biases in order to uphold the public service commitment to fairness that is important to public sector organizations. One way this can be done is by prioritizing fair hiring systems (Beattie \& Johnson, 2011).

Although researchers have identified hundreds of different types of biases (Ross, 2008), the scope of this Literature Review and research study will explore three types of biases that are more common in merit-based hiring processes: racial bias, gender bias, and nepotism/favoritism.

\section{Racial Bias}

Many assumptions can be made about someone based on just his or her name. A field research study was done in 2003 by Marianne Bertrand and Sendhil Mullainathan that aimed to measure racial discrimination in the labor market, and applicant names were the main variable studied. In their research, they discovered that African-American sounding names were discriminated 
against significantly (Bertrand \& Mullainathan, 2003). The researchers responded to 1,300 helpwanted ads from various Boston and Chicago newspapers with fake resumes. $50 \%$ of the resumes sent had "white sounding" names such as Greg Baker and the other 50\% were "AfricanAmerican" sounding names, such as Jamal Jones (Bertrand \& Mullainathan, 2003). Bertrand and Mullainathan included other components to their resumes, such as education levels and job experience. Bertrand and Mullainathan concluded that just on the basis of names, there were [...] large racial differences in callback rates. Applicants with White names need to send about 10 resumes to get one callback, whereas applicants with African American names need to send around 15 resumes to get one callback. This 50 percent gap in callback rates is statistically very significant. Based on our estimates, a White name yields as many more callbacks as an additional eight years of experience. Since applicants' names are randomly assigned [for this study], this gap can only be attributed to the name manipulation. (Bertrand \& Mullainathan, 2003)

These results clearly support the statement that names alone can impact an eligible candidate's likelihood of being hired. Bertrand and Mullainathan conclude that in hiring situations, a manager can read a name on a resume or eligibility list and, through unconscious and conscious biases, start to form judgements about a candidate. The hiring manager can read a name and it may not "sound right", may be too hard to pronounce, or a candidate's ethnicity may be assumed, and generalizations about their background can be made (Bertrand \& Mullainathan, 2003).

Another study by Carlsson and Rooth (2008) explored the racial discrimination that candidates faced in the early-stages of the hiring process due to "foreign sounding" names. These 
candidates were $77 \%$ less likely to be invited for an interview compared to a candidate who possessed a "native sounding" name (Carlsson \& Rooth, 2008). This notably affects the hiring entity's perception about the candidate, especially the candidate's qualifications, which should be the sole factor in a merit-based process. The unfortunate reality of these statistics is that, in the majority of instances, racial bias takes place before the candidate and employer are able to meet face-to-face (Carlsson \& Rooth, 2008). From the statistics collected from Carlsson and Rooth's study, it can be assumed that the probability of racial biases being present during the interview and selection steps of the hiring process is high. These are just a few of the possibilities that can take place, but all inevitably lead to the bias and/or discrimination entering the hiring process (Carlsson \& Rooth, 2008). These external factors have the potential to influence the civil service system and are detrimental to maintaining a merit-based process.

\section{Gender Bias}

If a city were to implement a fully de-identified hiring process, it would be similar to the study that was done by Goldin and Rouse in 1997. They studied the hiring process of symphony orchestras and tested for sex-biased hiring. Before revising audition policies in the 1980's, women musicians consisted of less than 5\% of the players in United States orchestras (Goldin \& Rouse 1997).

Goldin and Rouse conducted blind auditions to answer whether women were more likely to advance and/or be hired due to this additional phase in the hiring process, ultimately testing to see whether bias exists in the absence of face-to-face interaction with a candidate (Goldin \& Rouse 1997). The study is beneficial to this paper as it examines a core tenant that is applicable to any civil service hiring process: "[...] the issue is whether sex (or race or ethnicity), apart from objective criteria (e.g., the sound of musical performance; the content of a resume), is considered 
in the hiring process" (Goldin \& Rouse, 1997). The study concluded that blind auditions caused a $50 \%$ increase in the probability that a woman would advance and/or be hired by the orchestra (Goldin \& Rouse, 1997). Additionally, “[...] the blind auditions can explain between $30 \%$ and $55 \%$ of the increase in the proportion female among new hires [...]" (Goldin \& Rouse, 1997).

Another study comparing male and female applicants for a laboratory manager role found that gender had a significant effect on how the reviewer perceived the applicant's competence, employability, pay, and mentorship opportunities (Moss-Racusin, Dovidio, Brescoll, Graham, Handelsman, 2012). The findings stated that before any face-to-face contact, reviewers viewed female applicants as "less competent and less hirable" compared to male applicants with identical applications (Moss-Racusin et al, 2012). In addition to that, after interviews had taken place, all reviewers offered female applicants lower salaries compared to the male counterparts (Moss-Racusin et al, 2012). The findings of this study clearly demonstrated gender bias being present during the hiring process. The likelihood of gender bias continuing into the post-hiring process has been confirmed by research, as women are "[...] held back by company practices and structure that are biased towards men" (International Labour Organization, 2017).

These studies support the purpose of de-identification: the less contact (de-identified or not) a hiring manager/hiring department has with an eligible candidate, the fewer opportunities there are for biases and stereotypes to play a role in the hiring process. This idea proves that deidentifying helps control biases in the hiring process (Rinne, 2018). De-identification techniques, such as blind evaluations during the selection process and structured recruitment systems, can aid in minimizing the impact of gender bias in hiring decisions (Mertz, 2011). It is understandable that some city jobs cannot be filled by blind auditions or blind interviews, but these studies demonstrate that the implementation of de-identification methods decreases the likelihood of 
biases entering the hiring process (Goldin \& Rouse, 1997). The implementation of these techniques in any part of the civil service hiring processes (post-examination, during application screenings, before interviews, during selection) can be a reality for many cities. These studies and their findings can help cities see the negative impacts in current identifying hiring processes, and for cities to possibly consider the positive impacts de-identification measures can have on decreasing the likelihood of biases during hiring decisions (Rinne, 2018)

\section{Nepotism/Favoritism}

Organizations should implement new de-identification practices and measures to decrease the amount of "implicit bias" in their hiring process (McCormack, 2016). Nepotism is a type of bias that "refers to the act of favoritism in the hiring process" (Padgett \& Morris, 2005) in favor of relatives of the selecting authority, and is included in the type of bias CCSF hopes to decrease with the implementation of the new de-identification rules.

In the study conducted by Padgett and Morris (2005), nepotism and its affects are studied in a controlled hiring situation. The authors took a group of 197 students and assigned them to review three candidates for a managerial position. They were asked to select someone for the position using a merit-based and nepotism-based hiring method. The study concluded that the nepotism-based process was "[...] perceived as less fair than merit-based hiring, but individuals believed to have benefited from a family connection during the hiring process were viewed less favorably than individuals believed to have been hired based on merit" (Padgett \& Morris, 2005).

The authors stated that most professionals in business organizations regard nepotism as highly "negative" (Padgett \& Morris, 2005). Nepotism and favoritism are viewed as unfavorable ways to gain employment and for career advancement. Professionals perceive those who benefit from preferential selection as "unfavorable" and in turn, employees chosen for positions based 
on nepotistic decisions find it more difficult to be effective in their positions (Padgett \& Morris, 2005). Padgett and Morris also discovered that employees felt "less positively" about their employer if they used a nepotistic hiring process compared to a merit-based one. This influenced how employees felt about their job performance, concluding that "good job performance" was less likely to be rewarded when other non-merit factors were being considered (Padgett \& Morris, 2005). This is a significant issue for public agencies, as it can have negative effects on organizational culture, efficiency, can encourage behavioral problems, and reduce employee morale (Jones, 2012). These issues ultimately affect employee commitment and retention eventually increasing hiring and training costs for the organization. Yet, "[ $[.] 85 \$.$% of managers$ are still willing to practice nepotism in some circumstances [...]" (Padgett \& Morris, 2005).

The study concludes by stating that anti-nepotism policies must be in place for all organizations that want to hire using merit-based methods (Padgett \& Morris, 2005). Lastly, they suggest that organizations understand their individual hiring processes thoroughly (Padgett \& Morris, 2005). Both of these steps must be taken to address an organization's concerns for combating biases (Padgett \& Morris, 2005). Implementing these steps in the hiring process can decrease instances where nepotism and favoritism are used because they remind employees to use de-identification measures and refer to agency anti-nepotism policies (Sundell, 2014).

\section{Privacy in Public Sector Hiring}

Fully identified eligibility lists have the potential of infringing upon an individual's privacy rights (Roberts \& Doss, 1991). These issues and possible legal concerns surrounding privacy may be the motivation organizations need to update their de-identification practices; to better protect individual privacy concerns and thus, limiting illegal biases in the hiring process, especially during the post-examination period and selection process (Roberts \& Doss, 1991). 
The constitutional privacy rights of an individual protect their ability to make personal decisions unrelated to their employment or employer without concern from the public (Cozzetto \& Pedeliski, 1997). For example, what year an individual graduated should be irrelevant when an employer is making a decision to interview or hire a candidate - an employment decision should not be based on factors that are not job related (Cozzetto \& Pedeliski, 1997). Thus, the majority of identifying information available in CCSF's previous hiring process (prior to deidentification) allowed for the possibility for non-job related factors to be considered in the hiring of an employee. It can be argued that this is also a form of bias (Jones, 2012). A hiring manager may give preference to a candidate who attended the same school as he or she did over a candidate who possesses more qualified job experience but attended a different college (Bertrand \& Mullainathan, 2003). The merit-based hiring process should focus on knowledge, skills, and abilities demonstrated in the civil service test or resume evaluation, which is why deidentification measures can limit biases from occurring during the hiring process (Carlsson \& Rooth, 2008).

\section{Preventing Bias in Public Sector Hiring}

In the public sector, it is important to prevent biases from affecting the workplace and disrupting any job-related tasks and responsibilities, especially in the hiring process. In the public sector, any type of bias is considered a conflict of interest (and in some instances may be illegal), as it presents a conflict between an employee's public duty (upholding a merit-based process) and interference of private interest (bias) (Davids \& Boyce, 2008). Various de-identification measures are designed to mitigate bias issues, because de-identification measures are set up to remove information that might lead to biased decisions (Beattie \& Johnson, 2011). Deidentification within the public sector provides a structural process that instills commitment in 
the employee to serve the public in a fair and just way, so that the public's confidence in the public sector does not diminish (Davids \& Boyce, 2008).

Because biases are difficult to identify and prevent, current literature suggests that a perfect solution does not exist. Instead, mitigation options should be implemented to help eliminate bias in the hiring process. Organizations should use multiple strategies before, during, and after candidate review and post-selection to combat bias (Spearritt, 2018). This means that public sector organizations must create policies and protocols that guide employees toward specific procedures in order to conduct hiring that protects the merit-based process. A new employment procedure can be comprised of a series of policies and practices that guide an organization's approach to conducting hiring (Tetlock \& Mitchell, 2009). In order for the organization to conduct the successful implementation of any new employment procedure, the organization must take the responsibility to carefully assign relevant roles and responsibilities to the HR professionals involved in hiring decisions (Tetlock \& Mitchell, 2009). This includes deidentification measures, such as screening redacted job applications and/or scheduling interviews based on the highest scores on an eligibility list (Beattie \& Johnson, 2011). These are procedures that mitigate against the instances of biases in the hiring process (Mertz, 2011). The studies discussed in this Literature Review support CCSF's decision to de-identify its eligibility lists and use other hiring processes to decrease explicit and implicit biases. 


\section{FINDINGS}

A questionnaire was used to collect responses from the selected market cities to compare their eligibility list practices to CCSF's newly implemented rule reform of de-identifying eligibility lists when publicly posted and distributed. The questionnaire, attached under the Appendix, was comprised of twenty questions that focused on collecting procedural information regarding human resources practices of the selected government organizations (market cities), and the use of eligibility lists in the hiring process. The questionnaire's key areas of focus included:

- Centralized Human Resources Department - Do market cities have a dedicated human resources department that governs their hiring processes?

- Eligibility List Requirements - Are market cities required to have eligibility lists due to a specific law? Do these laws require that eligibility lists be publicly posted?

- Eligibility List Usage - What information is included on eligibility lists? What information is redacted from eligibility lists?

- Eligibility List Distribution - How are eligibility lists are distributed to the public and city departments?

- Complaints - Has the public posting of eligibility lists caused the market city to receive complaints?

Basic demographic information was also collected from each market city respondent.

\section{Questionnaire Results}

Nine market cities were selected for this questionnaire. Out of the nine cities, eight provided a completed response to the questionnaire. The only market city that did not submit a response to the questionnaire was Seattle, Washington. Charlotte, North Carolina stated that it does not use eligibility lists. The questionnaire was not distributed to the Office of Personnel Management 
(OPM) and they were not responsive to phone calls that were made to collect information on the management of their eligibility lists. But OPM's eligibility list practices are reflected in the applicable tables for comparisons to the market cities. The data on OPM's practices were collected from the official OPM website. If an agency did not complete the questionnaire, left a response to a question blank (or information was not available), it is denoted as "NR" (no response) or "NA" (not-applicable) within the tables.

\section{Questions 1-3.}

1. What city government are you currently an employee at?

2. What city department are you currently working for?

3. What is your role in your department or title of your position?

Table 3:

\begin{tabular}{|c|c|c|}
\hline Agency & Department Respondent & Respondent Role \\
\hline $\begin{array}{l}\text { Commonwealth of } \\
\text { Massachusetts }\end{array}$ & $\begin{array}{l}\text { Human Resources Division, Civil } \\
\text { Service Unit }\end{array}$ & $\begin{array}{l}\text { Human Resources } \\
\text { Department Head }\end{array}$ \\
\hline San Jose, CA & Department of Human Resources & Human Resources Analyst \\
\hline Austin, TX & Human Resources Department & Civil Service Administrator \\
\hline Jacksonville, FL & $\begin{array}{l}\text { Employee Services Department } \\
\text { (Human Resources) }\end{array}$ & $\begin{array}{l}\text { Human Resources } \\
\text { Specialist }\end{array}$ \\
\hline San Francisco, CA & Department of Human Resources & $\begin{array}{l}\text { Employment Services } \\
\text { Deputy Director }\end{array}$ \\
\hline Charlotte, NC & Human Resources & Administrative Staff \\
\hline Seattle, WA & NR & NR \\
\hline Detroit, MI & Department of Human Resources & $\begin{array}{l}\text { Human Resources } \\
\text { Department Head }\end{array}$ \\
\hline Denver, CO & Civil Service Commission & $\begin{array}{l}\text { Human Resources } \\
\text { Department Head }\end{array}$ \\
\hline OPM & NR & NR \\
\hline
\end{tabular}

Table 3 illustrates the market cities that participated in the survey, the department from which a response was received, and the role of the respondent within the department. 


\section{Question 4.}

Does your city have a centralized human resources office that regulates HR activities for all city departments?

Table 4:

\begin{tabular}{|c|c|c|}
\hline Agency & Yes & No \\
\hline Commonwealth of Massachusetts & & $\mathbf{X}$ \\
\hline San Jose, CA & $\mathbf{X}$ & \\
\hline Austin, TX & $\mathbf{X}$ & \\
\hline Jacksonville, FL & $\mathbf{X}$ & \\
\hline San Francisco, CA & $\mathbf{X}$ & \\
\hline Charlotte, NC & $\mathbf{X}$ & \\
\hline Seattle, WA & NR & \\
\hline Detroit, MI & $\mathbf{X}$ & \\
\hline Denver, CO & $\mathbf{X}$ & \\
\hline OPM & NA & \\
\hline
\end{tabular}

Question 4 aimed to reveal whether a city department's human resources processes are dictated by an overseeing agency. As anticipated, each market city does have an overseeing agency that determines the human resources practices for each department to follow.

Question 4 reveals that most market cities, with the exception of the Commonwealth of Massachusetts, have a centralized human resources office. It is assumed that the respondent from the Commonwealth of Massachusetts marked "No" because the Human Resources Division is the centralized human resources office for the State of Massachusetts. OPM is the centralized human resources office for the federal government. 


\section{Question 5.}

Does your agency use eligibility lists when filling any permanent civil service positions? (NOTE: an eligibility list may also be referred to as a "referral" list or "certification" list by varying city agencies/departments)

Table 5:

\begin{tabular}{|l|c|c|}
\hline \multicolumn{1}{|c|}{ Agency } & Yes & No \\
\hline \multicolumn{2}{|c|}{} \\
\hline Commonwealth of Massachusetts & X & \\
\hline San Jose, CA & X & \\
\hline Austin, TX & X & \\
\hline Jacksonville, FL & X & \\
\hline San Francisco, CA & X & \\
\hline Charlotte, NC & NR \\
\hline Seattle, WA & X & \\
\hline Detroit, MI & X & \\
\hline Denver, CO & X & \\
\hline OPM &
\end{tabular}

Question 5 reveals that all market cities, except the City of Charlotte, use eligibility lists to fill permanent civil service positions. OPM refers to its lists as "certificate of eligibles" (Office of Personnel Management, 2019)

Through e-mail correspondence, a City of Charlotte Talent Acquisition Management Assistant stated that the City of Charlotte "[...] do[es] not have a civil service merit system [...]". It is unclear as to what method the City of Charlotte uses to fill their permanent civil service positions. The City of Charlotte did not answer all questions for the remainder of the findings, questions that the City of Charlotte did not answer will be denoted with a "NA" for "not-applicable". 


\section{Question 5A.}

Based on your professional knowledge, which classifications use eligibility lists?

Table 6:

\begin{tabular}{|c|c|c|}
\hline 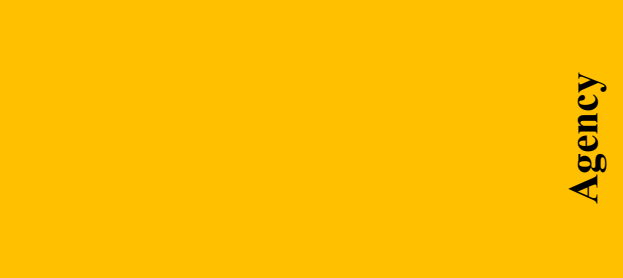 & 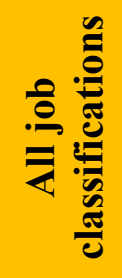 & 竞 \\
\hline Commonwealth of Massachusetts & & $\mathbf{X}$ \\
\hline San Jose, CA & & $\mathbf{X}$ \\
\hline Austin, TX & & $\mathbf{X}$ \\
\hline Jacksonville, FL & $\mathbf{X}$ & \\
\hline San Francisco, CA & $\mathbf{X}$ & \\
\hline Charlotte, NC & NA & \\
\hline Seattle, WA & NR & \\
\hline Detroit, MI & $\mathbf{X}$ & \\
\hline Denver, CO & & $\mathbf{X}$ \\
\hline OPM & NR & \\
\hline
\end{tabular}

Question 5A was revealed to a respondent only if Question 5 was answered as "Yes". This question aimed to reveal which job classifications use eligibility lists. Cities vary in what classifications use eligibility lists.

Positions that fall under the "sworn" classification are public safety positions such as police officers, fire fighters, and emergency dispatchers. Positions that fall under the "management" classification include directors, managers, and supervisors. Positions that fall under the "non-management" classification include clerical, technical, labor, administrative, and operations staff; the non-management classification is generally a broad classification that encompasses many positions. 
The answers for this question reveal that three market cities use eligibility lists to fill all permanent position classifications, this encompasses sworn, management, and non-management positions. Four cities use eligibility lists to fill sworn positions. The City of Detroit provided additional details stating that it uses eligibility lists for all classifications except "appointed, provisional, and special services classifications". 


\section{Question 6.}

Are the eligibility lists publicly posted?

Table 7:

\begin{tabular}{|c|c|c|c|}
\hline 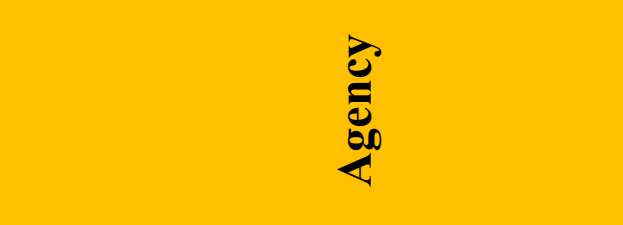 & $\stackrel{\theta}{\nu}$ & z & 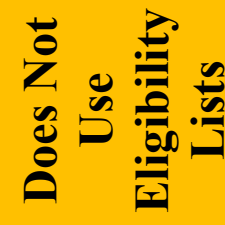 \\
\hline Commonwealth of Massachusetts & $\mathbf{X}$ & & \\
\hline San Jose, CA & & $\mathbf{X}$ & \\
\hline Austin, TX & $\mathbf{X}$ & & \\
\hline Jacksonville, FL & $\mathbf{X}$ & & \\
\hline San Francisco, CA & $\mathbf{X}$ & & \\
\hline Charlotte, NC & & & $\mathbf{X}$ \\
\hline Seattle, WA & NR & & \\
\hline Detroit, MI & & $\mathbf{X}$ & \\
\hline Denver, CO & $\mathbf{X}$ & & \\
\hline OPM & & & \\
\hline
\end{tabular}

Question 6 aimed to reveal whether market cities publicly post their eligibility lists.

The City of Charlotte does not use eligibility lists. The City of San Jose and the City of Detroit do not publicly post their eligibility lists. The Commonwealth of Massachusetts, City of Austin, City of Jacksonville, City of San Francisco, and the City of Denver publicly post their eligibility lists. 


\section{Question 6A.}

Where are the eligible lists posted and/or distributed to?

Table 8:

\begin{tabular}{|c|c|c|c|c|c|c|}
\hline 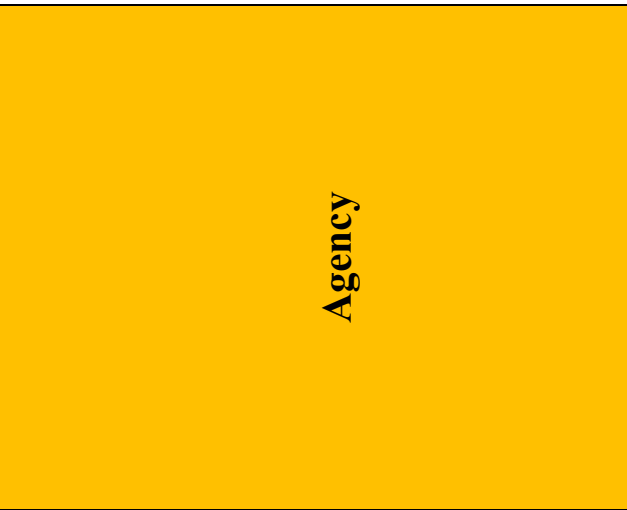 & 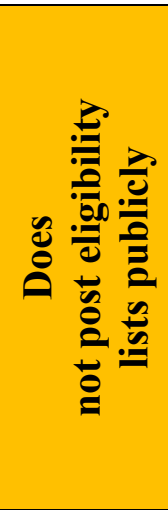 & 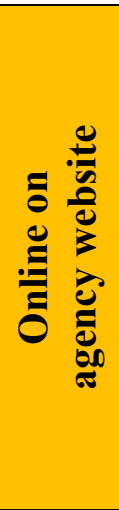 & 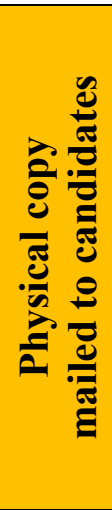 & 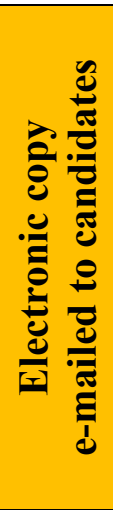 & 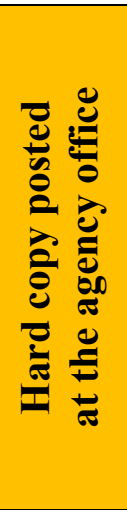 & 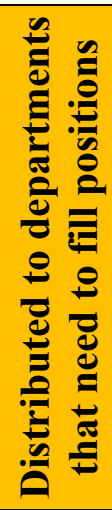 \\
\hline Commonwealth of Massachusetts & & $\mathbf{X}$ & & & & \\
\hline San Jose, CA & $\mathbf{X}$ & & & & & \\
\hline Austin, TX & & $\mathbf{X}$ & & $\mathbf{X}$ & $\mathbf{X}$ & \\
\hline Jacksonville, FL & & $\mathbf{X}$ & & & & $\mathbf{X}$ \\
\hline San Francisco, CA & & $\mathbf{X}$ & & & & \\
\hline Charlotte, NC & $\mathbf{X}$ & & & & & \\
\hline Seattle, WA & NR & & & & & \\
\hline Detroit, MI & & & $\mathbf{X}$ & & & \\
\hline Denver, CO & & $\mathbf{X}$ & & & & \\
\hline OPM & & & & & & $\mathbf{X}$ \\
\hline
\end{tabular}

Question 6A aimed to reveal where market cities publicly post their eligibility lists.

The City of San Jose does not have the practice of publicly posting its eligibility lists.

The City of Charlotte does not use eligibility lists, so does not post. The Commonwealth of Massachusetts, the City of Austin, the City of Jacksonville, the City of San Francisco, and the City of Denver have their eligibility lists available on the agency website for the public and other city departments to view. 
No city provides hard copies for the public to pick-up, print, or copy. The City of Detroit is the only market city that physically mails a copy of the eligibility list to candidates who took the examination. The City of Austin is the only city that e-mails an electronic copy of the eligibility list to candidates who took the examination. Additionally, the City of Austin also posts physical copies of eligibility lists at their agency office. Per the OPM website, the agency distributes its eligibility lists to departments that need to fill positions (Office of Personnel Management, 2019).

The City of Jacksonville distributes its eligibility lists to departments that need to fill the positions the eligibility list has been established for. The City of Jacksonville provided additional details stating, "The public can only request copies of eligibility lists through a Public Record Request only; online eligibility lists are available to city employees". From these details, it can be assumed that the City of Jacksonville takes an extra step to protect candidate information if eligibility lists can only be requested through a public records request, which is usually a lengthy process. This reinforces the research conducted by Beattie and Johnson (2011) where they concluded that de-identification measures are set up in order to protect information that may lead to biased judgements and decisions. 


\section{Question 7.}

Are eligibility lists posted/distributed with any personally identifying information about the candidate? (i.e. first and/or last name, gender, race, etc.)?

Table 9:

\begin{tabular}{|c|c|c|c|c|}
\hline 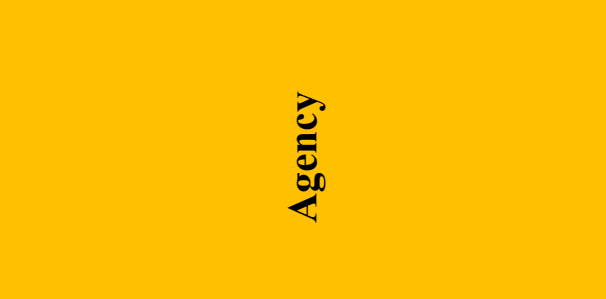 & $\stackrel{\nu}{~}$ & z & 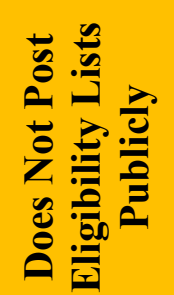 & 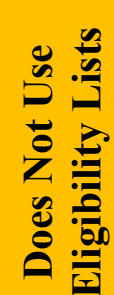 \\
\hline Commonwealth of Massachusetts & $\mathbf{X}$ & & & \\
\hline San Jose, CA & & & $\mathbf{X}$ & \\
\hline Austin, TX & $\mathbf{X}$ & & & \\
\hline Jacksonville, FL & $\mathbf{X}$ & & & \\
\hline San Francisco, CA & & $\mathbf{X}$ & & \\
\hline Charlotte, NC & & & & $\mathbf{X}$ \\
\hline Seattle, WA & NR & & & \\
\hline Detroit, MI & & & $\mathbf{X}$ & \\
\hline Denver, CO & & $\mathbf{X}$ & & \\
\hline OPM & NR & & & \\
\hline
\end{tabular}

Question 7 aimed to reveal whether market cities publicly post and/or distribute their eligibility lists with personally identifying information. Personally identifying information includes an individual's first, middle, or last name, gender, race, citizenship status, or other attributes.

The City of San Jose and the City of Detroit do not have the practice of publicly posting their eligibility lists. As revealed in Question 6A, the City of Detroit mails a physical copy of the eligibility list to the candidate. The City of Charlotte does not use eligibility lists, and therefore does not have a reason to publicly post them. The City of San Francisco and the City of Denver 
stated that they do not include personally identifying information on their eligibility lists. Essentially, this means that they take a de-identified approach to posting their lists. The Commonwealth of Massachusetts, the City of Austin, and the City of Jacksonville include personally identifying information on their eligibility lists - when publicly posted and distributed. 


\section{Question 8.}

Does your agency redact personally identifying information (i.e. names) before posting/distributing eligibility lists?

Table 10:

\begin{tabular}{|c|c|c|c|c|}
\hline 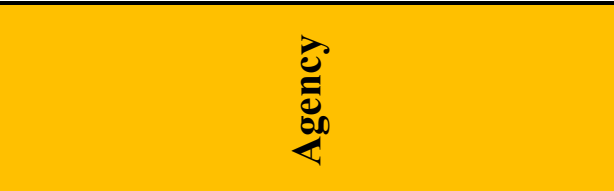 & $\stackrel{\theta}{\varnothing}$ & 之 & 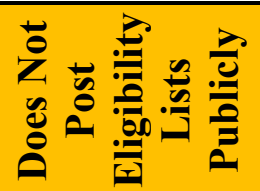 & 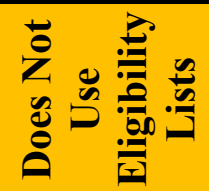 \\
\hline Commonwealth of Massachusetts & & $\mathbf{X}$ & & \\
\hline San Jose, CA & & & $\mathbf{X}$ & \\
\hline Austin, TX & & $\mathbf{X}$ & & \\
\hline Jacksonville, FL & & $\mathbf{X}$ & & \\
\hline San Francisco, CA & $\mathbf{X}$ & & & \\
\hline Charlotte, NC & & & & $\mathbf{X}$ \\
\hline Seattle, WA & NR & & & \\
\hline Detroit, MI & & & $\mathbf{X}$ & \\
\hline Denver, CO & $\mathbf{X}$ & & & \\
\hline OPM & NR & & & \\
\hline
\end{tabular}

Question 8 asked market cities if they take the additional step of redacting personally identifying information when they publicly post and/or distribute their eligibility lists.

The City of San Jose and the City of Detroit do not have the practice of publicly posting their eligibility lists. The City of Charlotte does not use eligibility lists, and therefore does not have a reason to publicly post them. The City of San Francisco and the City of Denver stated that they redact personally identifying information on their eligibility lists. To reiterate, this means that they take a de-identified approach to posting their lists. The Commonwealth of Massachusetts, the City of Austin, and the City of Jacksonville include personally identifying information on their eligibility lists - when publicly posted and distributed. 


\section{Question 9.}

What type of personally identifying information is included on the eligibility lists?

Table 11:

\begin{tabular}{|c|c|c|c|c|c|c|c|c|c|c|c|}
\hline 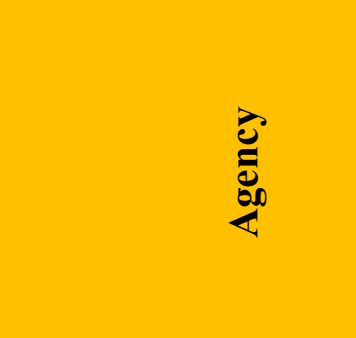 & & 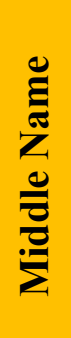 & 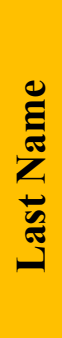 & 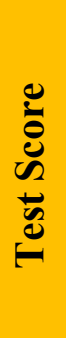 & 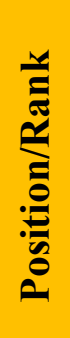 & 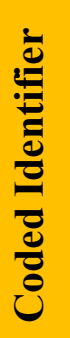 & 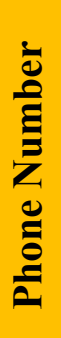 & 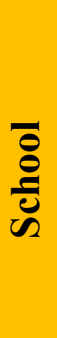 & 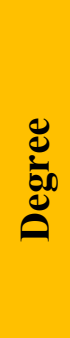 & 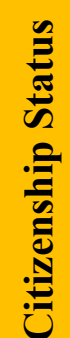 & 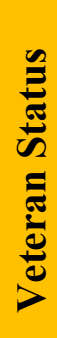 \\
\hline $\begin{array}{l}\text { Commonwealth of } \\
\text { Massachusetts }\end{array}$ & $\mathbf{X}$ & $\mathbf{X}$ & $\mathbf{X}$ & & $\mathbf{X}$ & & & & & & $\mathbf{X}$ \\
\hline San Jose, CA & $\mathbf{X}$ & & $\mathbf{X}$ & $\mathbf{X}$ & $\mathbf{X}$ & & & & & & \\
\hline Austin, TX & $\mathbf{X}$ & & $\mathbf{X}$ & $\mathbf{X}$ & $\mathbf{X}$ & & & & & & \\
\hline Jacksonville, FL & $\mathbf{X}$ & $\mathbf{X}$ & $\mathbf{X}$ & $\mathbf{X}$ & $\mathbf{X}$ & & $\mathbf{X}$ & $\mathbf{X}$ & $\mathbf{X}$ & $\mathbf{X}$ & $\mathbf{X}$ \\
\hline San Francisco, CA & & & & $\mathbf{X}$ & $\mathbf{X}$ & & & & & & \\
\hline \multicolumn{11}{|c|}{ Charlotte, NC NA } & \\
\hline Seattle, WA & NR & & & & & & & & & & \\
\hline Detroit, MI & $\mathbf{X}$ & & $\mathbf{X}$ & & $\mathbf{X}$ & & & & & & \\
\hline Denver, CO & & & & & $\mathbf{X}$ & $\mathbf{X}$ & & & & & \\
\hline OPM & NR & & & & & & & & & & \\
\hline
\end{tabular}

Question 9 asked the market cities about what personally identifying information is included on their eligibility lists. All of these items are considered to be personal information, when presented in a certain combination, they have the possibility of revealing the identity of the candidate and the candidate's personal information. Of the market cities, none included address on the list. No market city inquired about a candidate's year degree obtained, marital status, race, age, or gender on the list as these are all illegal questions to ask during the hiring process (Giang, 2013). 
The City of San Francisco and the City of Denver earlier identified as posting their eligibility lists in a de-identified form. When the City of San Francisco publicly posts its eligibility lists, it only includes the candidate's test score and the candidate's position/rank on the eligibility list. Additionally, the City of San Francisco stated that they also include "the number of eligibles in the rank". An example taken from their website is shown below in Figure 1.

Figure 1:

$\begin{array}{ll}\text { Eligible List Posting } & \text { Page } 1 \text { of } 1\end{array}$

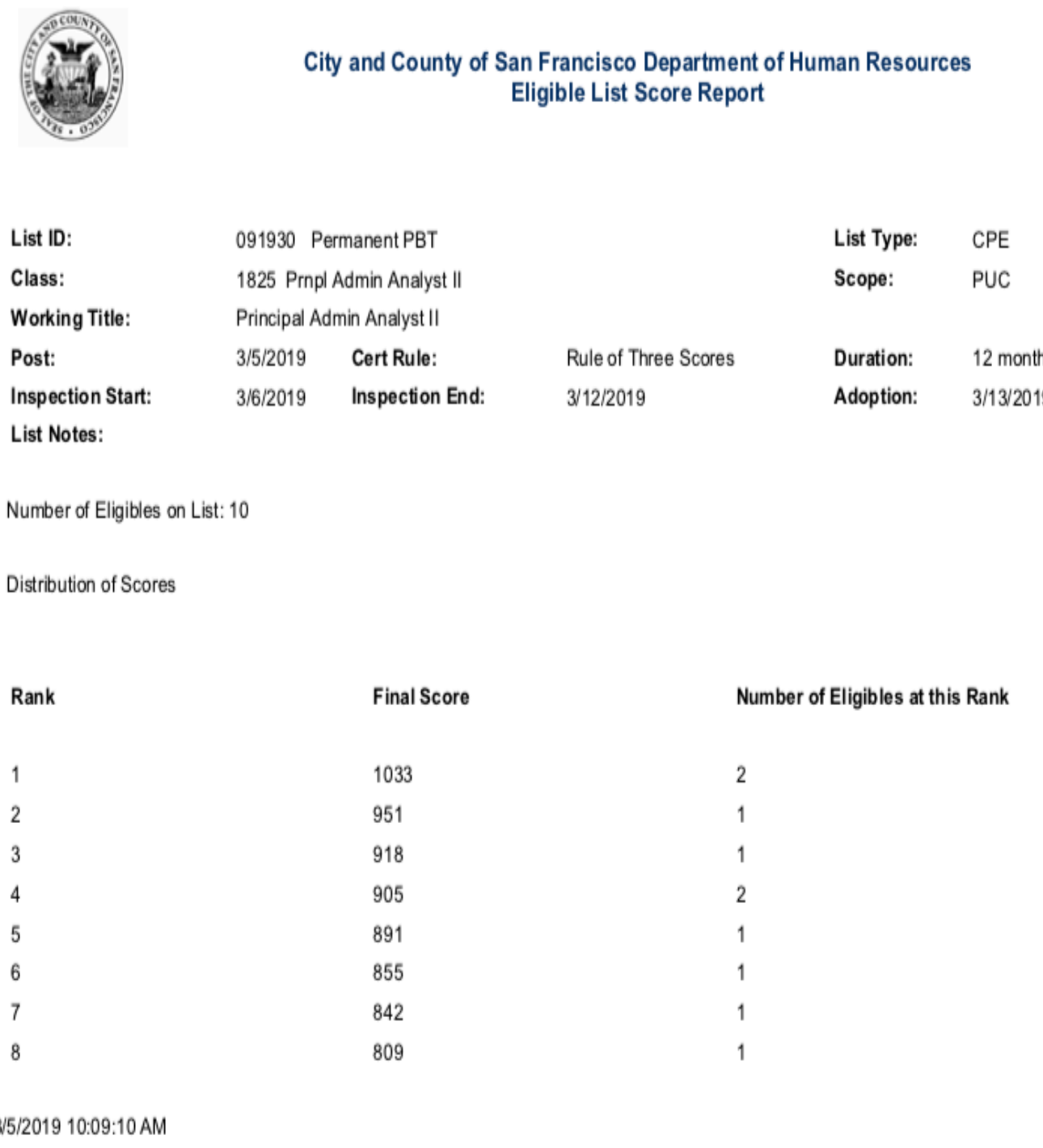


The City of Denver similarly includes the candidate's position/rank on the eligibility list along with a coded identifier individual to every candidate. These two market cities are examples of de-identifying eligibility lists.

The Commonwealth of Massachusetts and the cities of Austin and Jacksonville post their eligibility lists with personally identifying information. All three market cities include first and last names and the position/rank. The Commonwealth of Massachusetts and the City of Jacksonville include middle names and veteran status. Austin and Jacksonville both include test scores. Additionally, the City of Jacksonville also includes a candidate's phone number, school, degree, and citizenship status on the lists. The City of Jacksonville provided additional information regarding their eligible lists. They stated that Internal and external lists are treated differently: Internal lists include name and score. External lists are on a website (NEOGOV). When viewing the eligibility list in NEOGOV, the hiring manager can click on the applicant link and view the entire application, which may include name, address, phone number, email address, schools attended, degrees obtained, veteran and citizen status, and driver's license number (City of Jacksonville, 2019).

Bertrand and Mullainathan (2003) and Carlsson and Rooth (2008) determined that a name is more than enough information for biases to be created in the hiring process; a name alone can impact a candidate's hireability. An example of an eligibility list from the Commonwealth of Massachusetts is shown below in Figure 2. 
Figure 2:

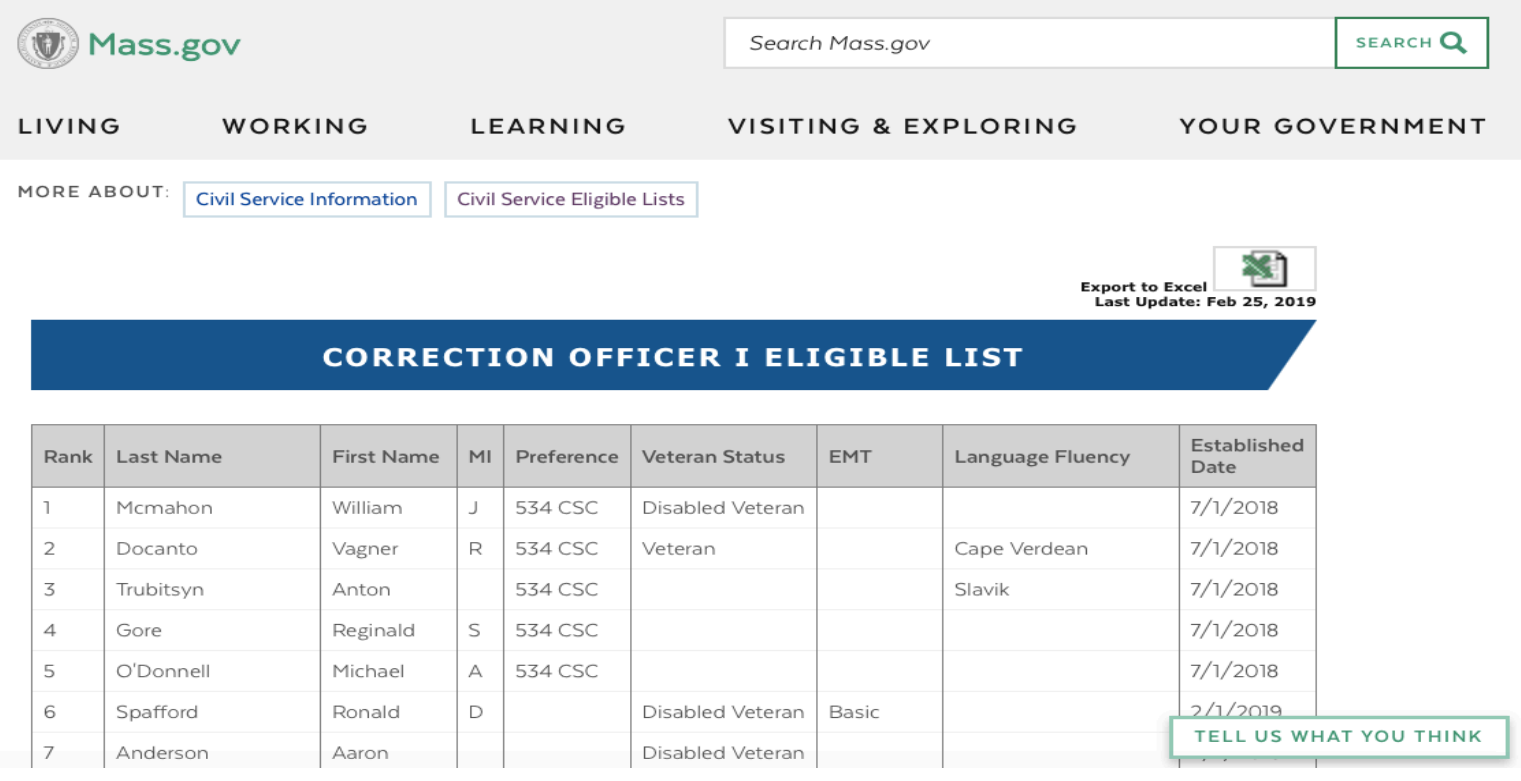

Although the City of San Jose and the City of Detroit do not have the practice of publicly posting their eligibility lists, they still distribute the lists to departments that need to fill positions. When they do this, both cities include first and last names and the candidate's position/rank on the eligibility list. The City of Charlotte does not use eligibility lists. 


\section{Question 10.}

If names are not used on the eligibility list, is the candidate assigned a coded identifier on the eligibility list?

Table 12:

\begin{tabular}{|c|c|c|c|}
\hline Agency & Yes & No & Uses names on Eligibility Lists \\
\hline Commonwealth of Massachusetts & & & $\mathbf{X}$ \\
\hline San Jose, CA & & & $\mathbf{X}$ \\
\hline Austin, TX & & & $\mathbf{X}$ \\
\hline Jacksonville, FL & & & $\mathbf{X}$ \\
\hline San Francisco, CA & & $\mathbf{X}$ & \\
\hline \multicolumn{4}{|l|}{ Charlotte, NC } \\
\hline Seattle, WA & \multicolumn{3}{|l|}{ NR } \\
\hline Detroit, MI & & & $\mathbf{X}$ \\
\hline Denver, CO & $\mathbf{X}$ & & \\
\hline OPM & & & \\
\hline
\end{tabular}

Question 10's findings confirm that Denver is the only market city that uses a coded identifier in lieu of a candidate's name. The City of San Francisco does not use coded identifiers. Once an eligible list is posted, the department that needs to fill a position must contact the Department of Human Resources to request a certification list to select candidates to interview (T. Tran, personal communication, 2019). This means that a candidate's identity is not revealed until the interview selection process. This is San Francisco's attempt to mitigate bias in the hiring process, but it raises questions about whether or not this process pushes off bias formation for later in the hiring process. The remaining six market cities use names on their eligibility lists. 


\section{Question 11.}

If your agency uses coded identifiers on the eligibility list, how are coded identifiers assigned?

Table 13:

\begin{tabular}{|c|c|c|}
\hline 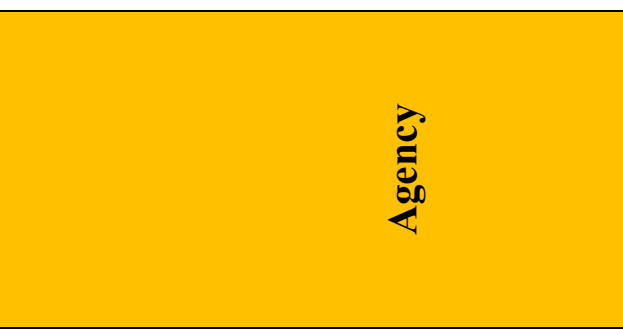 & 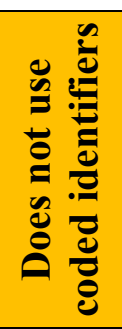 & 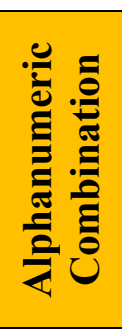 \\
\hline Commonwealth of Massachusetts & $\mathbf{X}$ & \\
\hline San Jose, CA & $\mathbf{X}$ & \\
\hline Austin, TX & $\mathbf{X}$ & \\
\hline Jacksonville, FL & $\mathbf{X}$ & \\
\hline San Francisco, CA & $\mathbf{X}$ & \\
\hline Charlotte, NC & NA & \\
\hline Seattle, WA & NR & \\
\hline Detroit, MI & $\mathbf{X}$ & \\
\hline Denver, CO & & $\mathbf{X}$ \\
\hline
\end{tabular}

Denver is the only market city that uses a coded identifier. It assigns a coded identifier with an alphanumeric combination of letters and numbers. As illustrated in Figure 1, San Francisco has completely de-identified its eligibility list. If a hiring manager wanted to interview a candidate from the list, he or she would have to contact the departmental human resources analyst to obtain the information necessary to schedule an interview. 


\section{Question 12.}

How are candidates informed about their scores and ranks on an eligibility list?

Table 14:

\begin{tabular}{|c|c|c|c|c|c|}
\hline 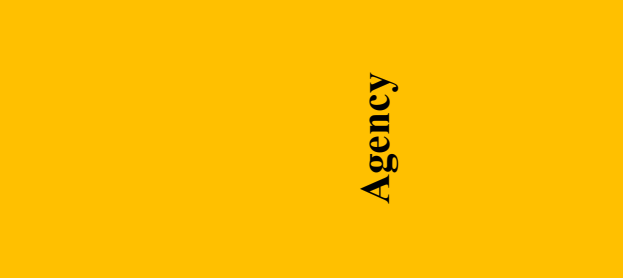 & 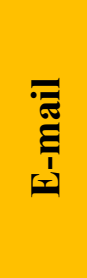 & 樆 & 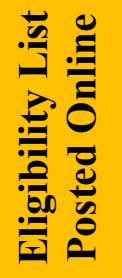 & $\frac{\dot{\Xi}}{\overline{0}}$ & 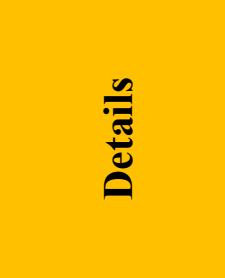 \\
\hline Commonwealth of Massachusetts & $\mathbf{X}$ & & $\mathbf{X}$ & & \\
\hline San Jose, CA & $\mathbf{X}$ & $\mathbf{X}$ & & & \\
\hline Austin, TX & $\mathbf{X}$ & & $\mathbf{X}$ & & \\
\hline Jacksonville, FL & $\mathbf{X}$ & & $\mathbf{X}$ & & \\
\hline San Francisco, CA & $\mathbf{X}$ & & $\mathbf{X}$ & & \\
\hline Charlotte, NC & NA & & & & \\
\hline Seattle, WA & NR & & & & \\
\hline Detroit, MI & & & & $\mathbf{X}$ & $\begin{array}{c}\text { Distributed } \\
\text { upon } \\
\text { request }\end{array}$ \\
\hline Denver, CO & $\mathbf{X}$ & & $\mathbf{X}$ & & \\
\hline OPM & NR & & & & \\
\hline
\end{tabular}

Question 12 answered how market cities inform candidates on their scores and ranks on an eligibility list.

None of the market cities call to inform candidates. The City of Charlotte does not use eligibility lists. The Commonwealth of Massachusetts and the cities of San Jose, Austin, Jacksonville, San Francisco, and Denver inform candidates via email. The City of San Jose is the only market city that informs candidates via a mailed letter. The City of Detroit only distributes eligibility lists upon request. Lastly, the cities of San Jose, Austin, Jacksonville, San Francisco, and the Commonwealth of Massachusetts posts eligibility lists online for the public, the 
candidates, and city professionals to view. OPM states that they " $[\ldots]$ will notify applicants of the status of their applications i.e. whether they were determined eligible or ineligible for the position" (Office of Personnel Management, 2019, n.p). 


\section{Question 13.}

Is your agency required by any law, legal policies, and/or rules to redact personally identifying information on eligibility lists?

Table 15:

\begin{tabular}{|l|c|c|}
\hline \multicolumn{1}{|c|}{ Agency } & Yes & No \\
\hline \multicolumn{1}{|c|}{ X } & \\
\hline Commonwealth of Massachusetts & & X \\
\hline San Jose, CA & & X \\
\hline Austin, TX & X & \\
\hline Jacksonville, FL & X & \\
\hline San Francisco, CA & NA \\
\hline Charlotte, NC & NR \\
\hline Seattle, WA & X & \\
\hline Detroit, MI & X & \\
\hline Denver, CO & NR \\
\hline OPM
\end{tabular}

Question 13 aimed to learn if agencies are legally required to protect a candidate's personally identifying information.

All market cities except for San Jose and Austin answered "Yes". This is an interesting finding, especially since the City of San Jose does not publicly post its eligibility lists. The assumption that the City of San Jose aims to protect candidate information without being legally required to, means that they truly seek to serve the public in a fair and just way (Davids \& Boyce, 2008). 


\section{Question 13A.}

Which of these laws, legal policies, or rules require you to redact personal identifying information from eligibility lists?

Table 16:

\begin{tabular}{|c|c|c|c|c|c|c|}
\hline 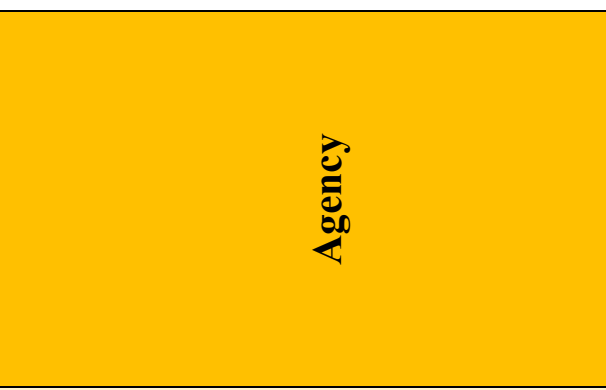 & 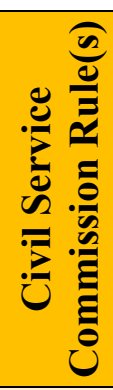 & 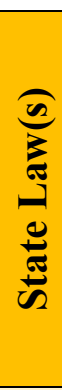 & 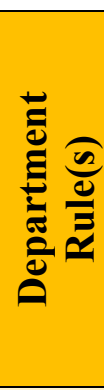 & 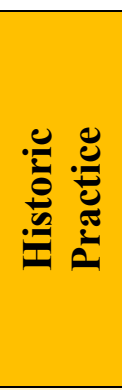 & 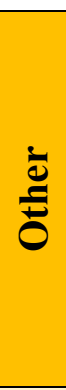 & 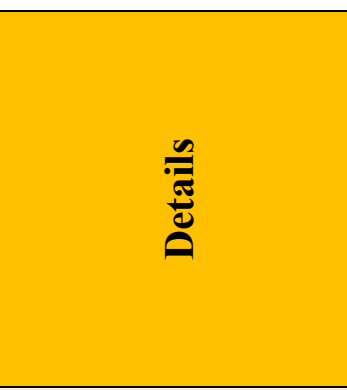 \\
\hline Commonwealth of Massachusetts & \multirow{2}{*}{\multicolumn{6}{|c|}{ NR }} \\
\hline San Jose, CA & & & & & & \\
\hline Austin, TX & \multicolumn{6}{|l|}{ NR } \\
\hline Jacksonville, FL & & & & $\mathbf{X}$ & & \\
\hline San Francisco, CA & $\mathbf{X}$ & & & & & \\
\hline Charlotte, NC & \multicolumn{6}{|l|}{ NA } \\
\hline Seattle, WA & \multicolumn{6}{|l|}{ NR } \\
\hline Detroit, MI & & $\mathbf{X}$ & & & $\mathbf{X}$ & Federal Standards \\
\hline Denver, CO & $\mathbf{X}$ & & $\mathbf{X}$ & $\mathbf{X}$ & & \\
\hline OPM & \multicolumn{6}{|l|}{ NR } \\
\hline
\end{tabular}

Question 13A tried to gauge what laws, legal policies, or rules required market cities to redact personally identifying information.

The cities of San Jose and Austin did not respond, as they are not required by any laws, legal policies, or rules to redact personally identifying information from their eligibility lists. Any redacting they do is voluntarily done by the specific departments. The City of Charlotte does not use eligibility lists. No city is required to redact by any city ordinance(s) or department process(es). 
The City of San Francisco redacts due to the rules of the Civil Service Commission. The decision for the new de-identified rule reform came from the San Francisco Civil Service Commission. The Commonwealth of Massachusetts and the cities of Austin and Detroit redact due to state laws. The Commonwealth of Massachusetts stated that "The Secretary of State determines scores are not public information. Additionally, Federal Court consent decree order in place for few municipalities ensures scores are not posted". That makes Massachusetts and Detroit the only market cities that take federal law into consideration for redaction purposes. The cities of Jacksonville and Denver redact due to historic practices. This means that the departments may have been conducting certain hiring processes for "X" amount of years, it has always been the norm. Lastly, the City of Denver also redacts due to rules by the Civil Service Commission and various city ordinances. 


\section{Question 14.}

Has your agency ever received complaints, appeals, or protests about the public posting of eligibility lists?

Table 17:

\begin{tabular}{|l|c|c|}
\hline \multicolumn{1}{|c|}{ Agency } & Yes & No \\
\hline \multicolumn{2}{|c|}{} \\
\hline Commonwealth of Massachusetts & X \\
\hline San Jose, CA & & X \\
\hline Austin, TX & X \\
\hline Jacksonville, FL & X & \\
\hline San Francisco, CA & NA \\
\hline Charlotte, NC NR \\
\hline Seattle, WA & & X \\
\hline Detroit, MI & & X \\
\hline Denver, CO & NR \\
\hline OPM
\end{tabular}

Question 14 produced interesting results. Every market city that participated in the questionnaire, except for San Francisco, answered "No" to receiving complaints about the public posting of eligibility lists.

It can be safely assumed that the cities of San Jose and Charlotte answered "No" because San Jose does not publicly post its lists and Charlotte does not use eligibility lists. The City of Denver de-identifies its eligibility lists, so it is understandable that they have not received complaints, appeals, or protests. The Commonwealth of Massachusetts and the cities of Austin, Jacksonville, and Detroit do not de-identify their eligibility lists, yet they still have not received complaints, appeals, or protests regarding the public posting of their eligibility lists. The possible reasoning behind these findings will be discussed in the analysis section of this study. 


\section{Question 14A.}

Which of the following complaints has your agency received?

Table 18:

\begin{tabular}{|c|c|}
\hline Agency & Complaints Received \\
\hline \multirow[t]{4}{*}{ San Francisco, CA } & Candidate embarrassment about applying for public job \\
\hline & Candidate concern about current employer seeing name on list \\
\hline & Candidate embarrassment about position on list \\
\hline & Candidate concern on nepotistic hiring decision(s) \\
\hline
\end{tabular}

Question 14A was only relevant to the City of San Francisco, since it was the only city that stated that it received complaints, appeals, or protests regarding the public posting of their eligibility lists. As anticipated, San Francisco received complaints on candidate concerns on nepotistic hiring decisions, which was the impetus for the new civil service rule reform. 


\section{Question 15.}

Are you required to redact any personally identifying information (i.e. names) before distributing eligibility lists to the individual(s) and/or team making the hiring decision?

Table 19:

\begin{tabular}{|l|c|c|}
\hline \multicolumn{1}{|c|}{ Agency } & Yes & No \\
\hline \multicolumn{2}{|c|}{} & \\
\hline Commonwealth of Massachusetts & & X \\
\hline San Jose, CA & & X \\
\hline Austin, TX & & X \\
\hline Jacksonville, FL & & X \\
\hline San Francisco, CA & NA & \\
\hline Charlotte, NC NR & \\
\hline Seattle, WA & X & \\
\hline Detroit, MI & & X \\
\hline Denver, CO & NR \\
\hline OPM
\end{tabular}

All market cities, except for San Francisco and Detroit, are either required to redact personally identifying information (i.e. names) before distributing eligibility lists to the individual(s) and/or team making the hiring decision, or they redact by practice. The City of Charlotte does not use eligibility lists. The City of Charlotte representative provided details stating that "Individual(s) and/or team making the hiring decision never see a redacted OR unredacted Eligibility List" because Charlotte does not use eligibility lists. 


\section{Question 16.}

When are the individual(s) and/or team making the hiring decision provided with the personally identifying information about the candidates that have moved further on in the hiring process?

Table 20:

\begin{tabular}{|c|c|c|c|c|c|c|c|c|}
\hline 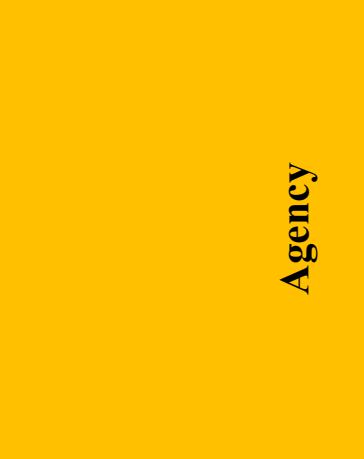 & 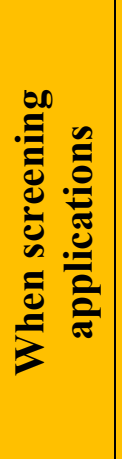 & 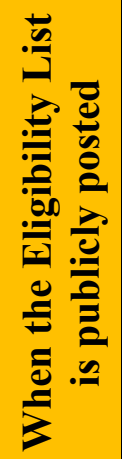 & 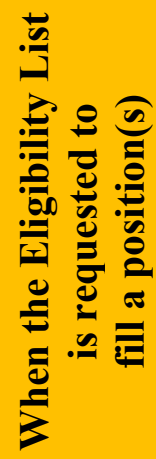 & 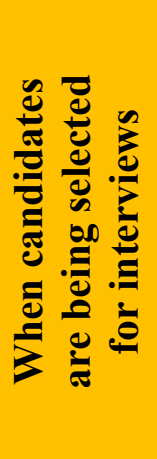 & 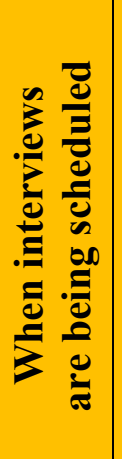 & 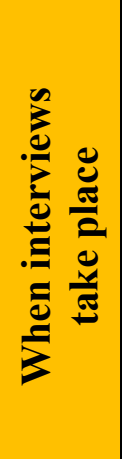 & $\begin{array}{l}\grave{D} \\
\bar{z}\end{array}$ & 㐫 \\
\hline $\begin{array}{l}\text { Commonwealth of } \\
\text { Massachusetts }\end{array}$ & & & & & & & & $\mathbf{X}$ \\
\hline San Jose, CA & & & $\mathbf{X}$ & $\mathbf{X}$ & $\mathbf{X}$ & $\mathbf{X}$ & & \\
\hline Austin, TX & $\mathbf{X}$ & $\mathbf{X}$ & $\mathbf{X}$ & & & & & \\
\hline Jacksonville, FL & & $\mathbf{X}$ & $\mathbf{X}$ & $\mathbf{X}$ & $\mathbf{X}$ & $\mathbf{X}$ & & \\
\hline San Francisco, CA & & & & & $\mathbf{X}$ & $\mathbf{X}$ & & \\
\hline Charlotte, NC & & & & & & & $\mathbf{X}$ & \\
\hline \multicolumn{9}{|l|}{ Seattle, WA } \\
\hline Detroit, MI & & & $\mathbf{X}$ & & & & & \\
\hline Denver, CO & & & $\mathbf{X}$ & & & & & \\
\hline OPM & NR & & & & & & & \\
\hline
\end{tabular}

Question 16 provides a clearer picture on how eligibility lists are distributed internally within city departments. Questions 17, 17A, and 17B will cover the information included on the eligibility lists. 
Charlotte does not provide hiring departments with eligibility lists since it does not use them. The cities of Detroit and Denver only release eligibility lists when departments request to fill a position. Austin is the only market city that provides eligibility lists to the hiring department during the application screening process. The hiring department also has access to the lists when they are publicly posted for the candidates and when the department requests to fill any position. San Jose provides the hiring department with an eligibility list when there is a request to fill a position, when the department is selecting candidates for interviews, and when interviews are taking place. Jacksonville is similar, but it includes providing the eligibility lists when they are publicly posted. The City of Jacksonville provided additional details stating The internal eligibility list, including names/scores only, is available to decision-makers as soon as it is certified and posted on the Employee Services internal website and throughout the hiring process. Decision-makers may see External candidates' entire application once the eligibility list is finalized and made available to them. This information is available to them during the entire hiring process (City of Jacksonville, 2019).

Since San Francisco has taken a de-identified approach, they only provide eligibility lists when interviews are being scheduled and when interviews are taking place. The Commonwealth of Massachusetts "[...] sends list to municipalities for hiring consideration. At that time the police and fire departments screen candidates for hire. All departments have an extensive background packet candidates must fill out. Some of the identifying information may be obtained at that time" (2019). 


\section{Question 17.}

What type of eligibility list is provided to the individual(s) and/or team making the hiring decision?

Table 21:

\begin{tabular}{|c|c|c|}
\hline Agency & $\begin{array}{c}\text { Redacted } \\
\text { (i.e. does not include } \\
\text { personally identifying } \\
\text { information) }\end{array}$ & $\begin{array}{c}\text { Un-redacted } \\
\text { (i.e. includes } \\
\text { personally } \\
\text { identifying } \\
\text { information) }\end{array}$ \\
\hline Commonwealth of Massachusetts & $\mathbf{X}$ & \\
\hline San Jose, CA & & $\mathbf{X}$ \\
\hline Austin, TX & & $\mathbf{X}$ \\
\hline Jacksonville, FL & & $\mathbf{X}$ \\
\hline San Francisco, CA & $\mathbf{X}$ & \\
\hline Charlotte, NC & NA & \\
\hline Seattle, WA & NR & \\
\hline Detroit, MI & $\mathbf{X}$ & \\
\hline Denver, CO & & $\mathbf{X}$ \\
\hline OPM & NR & \\
\hline
\end{tabular}

From the answers collected from Question 16, market cities stated what type of list hiring departments receive during the hiring process.

The Commonwealth of Massachusetts and the cities of San Jose, Austin, Jacksonville, and Denver provide an un-redacted list during the hiring steps outlined in their answers from Question 16. San Francisco and Detroit continue to provide a redacted list during the hiring steps outlined in their answers from Question 16. 


\section{Question 17A.}

What is removed [from the redacted eligibility lists]?

Table 22:

\begin{tabular}{|c|c|c|c|c|c|c|c|c|c|c|c|}
\hline 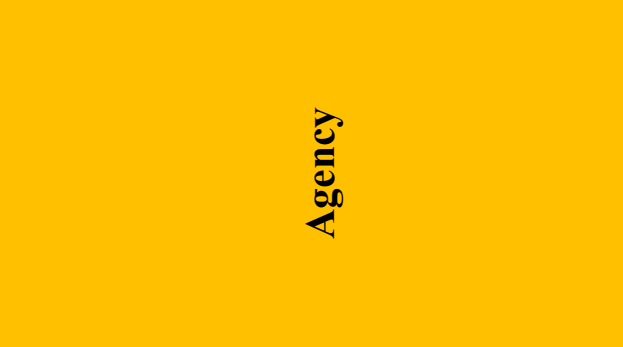 & 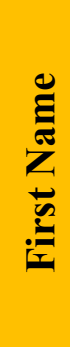 & 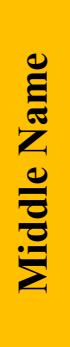 & 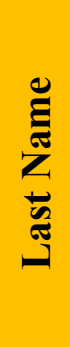 & 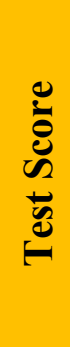 & 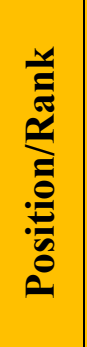 & 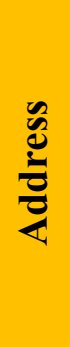 & 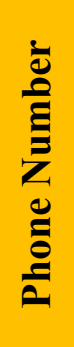 & $\begin{array}{l}\bar{O} \\
\bar{e} \\
\bar{e}\end{array}$ & 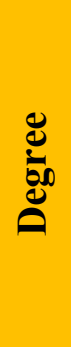 & 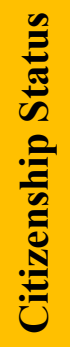 & 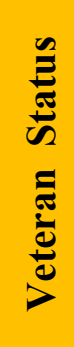 \\
\hline Commonwealth of Massachusetts & & & & $\mathbf{X}$ & & $\mathbf{X}$ & $\mathbf{X}$ & $\mathbf{X}$ & $\mathbf{X}$ & $\mathbf{X}$ & $\mathbf{X}$ \\
\hline San Francisco, CA & $\mathbf{X}$ & $\mathbf{X}$ & $\mathbf{X}$ & & & $\mathbf{X}$ & $\mathbf{X}$ & $\mathbf{X}$ & $\mathbf{X}$ & $\mathbf{X}$ & $\mathbf{X}$ \\
\hline Detroit, MI & & & & $\mathbf{X}$ & & $\mathbf{X}$ & $\mathbf{X}$ & $\mathbf{X}$ & $\mathbf{X}$ & $\mathbf{X}$ & $\mathbf{X}$ \\
\hline
\end{tabular}

Question 17A is only applicable to the Commonwealth of Massachusetts and the cities of San Francisco, and Detroit. Charlotte does not use eligibility lists and Seattle did not respond. All three market cities remove addresses, phone numbers, school, degrees, citizenship status, and veteran status from the redacted lists sent to hiring departments. San Francisco is the only market city that does not provide the hiring department with names on the lists. The hiring department will only receive candidate names when they have selected candidates for interviews (T. Tran, personal communication, 2019). 


\section{Question 17B.}

What is listed [on the un-redacted eligibility lists]?

Table 23:

\begin{tabular}{|c|c|c|c|c|c|c|c|c|c|c|c|}
\hline 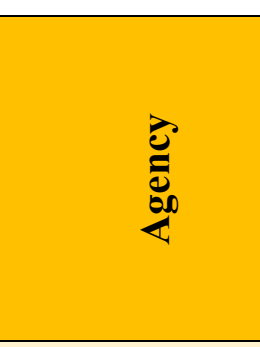 & 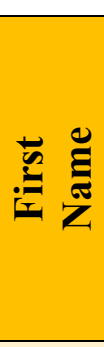 & 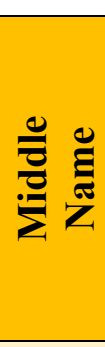 & 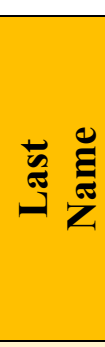 & 密 & 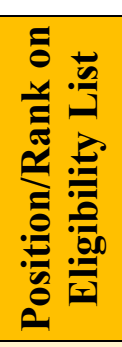 & $\frac{n}{\frac{n}{2}}$ & 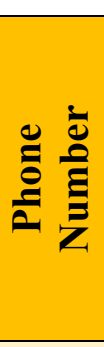 & $\begin{array}{l}\overline{8} \\
\bar{e} \\
\dot{E}\end{array}$ & 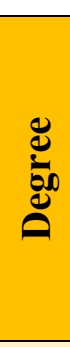 & 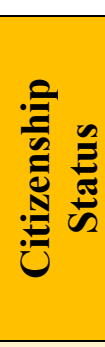 & 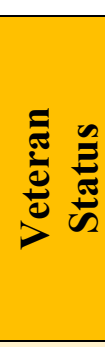 \\
\hline San Jose, CA & $\mathbf{X}$ & & $\mathbf{X}$ & $\mathbf{X}$ & $\mathbf{X}$ & & & & & & \\
\hline Austin, TX & $\mathbf{X}$ & $\bar{X}$ & & $\mathbf{X}$ & $\mathbf{X}$ & & & & & & \\
\hline $\begin{array}{l}\text { Jacksonville, } \\
\text { FL }\end{array}$ & $\mathbf{X}$ & $\mathbf{X}$ & $\mathbf{X}$ & $\mathbf{X}$ & & $\mathbf{X}$ & $\mathbf{X}$ & $\mathbf{X}$ & $\mathbf{X}$ & $\mathbf{X}$ & $\mathbf{X}$ \\
\hline Denver, CO & $\mathbf{X}$ & $\mathbf{X}$ & $\mathbf{X}$ & & $\mathbf{X}$ & & & & & & \\
\hline
\end{tabular}

All four market cities list first and last names on the un-redacted eligibility lists distributed to hiring departments. San Jose is the only city that does not list the middle name. All market cities except for Denver, list the test scores. All market cities except for Jacksonville, list the position/rank of the candidates on the list. Additionally, Jacksonville lists addresses, phone numbers, school, degrees, citizenship and veteran statuses on their lists. 


\section{Question 18.}

Based on your professional knowledge, do other departments within your agency redact personally identifying information from eligibility lists when using internal selection processes?

Table 24:

\begin{tabular}{|l|c|c|c|}
\hline \multicolumn{1}{|c|}{ Agency } & Yes & No & $\begin{array}{c}\text { Not allowed to use } \\
\text { own selection processes }\end{array}$ \\
\hline \multicolumn{3}{|l|}{} \\
\hline Commonwealth of Massachusetts & X & & X \\
\hline San Jose, CA & & & X \\
\hline Austin, TX & & & \\
\hline Jacksonville, FL & & X & \\
\hline San Francisco, CA & X & & \\
\hline Charlotte, NC & NA & \\
\hline Seattle, WA & NR & \\
\hline Detroit, MI & X & & \\
\hline Denver, CO & X & \\
\hline OPM & NR & \\
\hline
\end{tabular}

Question 18 sought to learn if further redaction takes place within intradepartmental hiring processes. Internal hiring processes are selection processes that individual departments use separate from their centralized human resources hiring processes. Departments of the Commonwealth of Massachusetts and the cities of San Francisco, Detroit, and Denver continue to redact within their internal department hiring processes. Departments with the city of Jacksonville does not further redact in its internal hiring processes. The cities of San Jose and Austin are not allowed to have their own internal selection processes, which means they are only able to implement the hiring processes that are dictated by their centralized human resources office. Lastly, the City of Charlotte does not use eligibility lists. 


\section{Question 19.}

Based on your professional knowledge, does your city have anti-nepotism laws or policies in place?

Table 25:

\begin{tabular}{|l|c|c|}
\hline \multicolumn{1}{|c|}{ Agency } & Yes & No \\
\hline \multicolumn{2}{|c|}{} \\
\hline Commonwealth of Massachusetts & X & \\
\hline San Jose, CA & X & \\
\hline Austin, TX & X & \\
\hline Jacksonville, FL & X & \\
\hline San Francisco, CA & X & \\
\hline Charlotte, NC & X & \\
\hline Seattle, WA & NR \\
\hline Detroit, MI & & \\
\hline Denver, CO & X & \\
\hline OPM & X & \\
\hline
\end{tabular}

Question 19 addressed the legal requirements to avoid nepotism within the hiring process of the selected market cities.

All market cities, except for Detroit, have anti-nepotism laws in place. OPM has federal standards and laws in place for nepotism (U.S. Merit Systems Protection Board, 2016). Antinepotism laws are important to have in place as they keep public agencies, and those within agencies in charge of making hiring decisions, legally accountable for the hiring decisions that they make. 


\section{Question 20.}

Based on your professional knowledge, does your agency provide bias training to human resources professionals across all city departments?

Table 26:

\begin{tabular}{|l|c|}
\hline \multicolumn{1}{|c|}{ Agency } & Yes \\
\hline Commonwealth of Massachusetts & \\
\hline San Jose, CA & X \\
\hline Austin, TX & X \\
\hline Jacksonville, FL & X \\
\hline San Francisco, CA & X \\
\hline Charlotte, NC & X \\
\hline Seattle, WA & NR \\
\hline Detroit, MI & X \\
\hline Denver, CO & X \\
\hline OPM & $\mathbf{X}$ \\
\hline
\end{tabular}

Question 20 addresses bias, a topic that hiring professionals must be educated about, especially professionals whose responsibility it is to promote diversity within the workplace.

Beattie and Johnson (2011) stated that one way to promote fair hiring systems is to make sure that the employees of the organization are educated on how biases effect their judgements and decisions about work related items. All market cities stated that they provide bias training for their human resources employees, including employees across all departments within the city who participate in the hiring processes. OPM also states on their official website that they provide annual bias training to their employees (Office of Personnel Management, 2019). This is a promising finding, since it illustrates that all market cities consider bias avoidance an important ethic to instill in their employees, leading to better informed decisions in the hiring process. 


\begin{abstract}
ANALYSIS
The intent of this analysis is to determine whether the market cites use de-identification practices different from CCSF when using eligibility lists for filling permanent civil service positions. This section will also include a discussion and evaluation of the de-identification practices and processes that the market cities have shared, to create the best practices benchmark for San Francisco and other public sector organizations to implement in their hiring processes.

The Analysis section of this study benchmarks the data as discussed in the Findings section to compare the eligibility list practices of the market cities. The Findings section examines the results of the questionnaire and provides details on comparable eligibility list practices and processes. The process intervention will analyze the best practices of deidentification techniques among the market cities, and will suggest how CCSF's de-identification process is in conformance with the best practices collected from the market cities.
\end{abstract}

\title{
Phase I: Process Intervention
}

\section{Problem Identification.}

This study identified the problem as publicly posting eligibility lists with personally identifying information leading to possible biases in the public sector hiring process. The main issues presented were:

1. Publishing the eligibility lists to the public when personally identifiable information would be embarrassing, or anger, and prejudice current employers.

- This raised concerns regarding the candidate's current employer(s) could possibly react badly to the news that the employee was seeking a different job.

- Candidate's complaining that publishing the lists publicly with fully identified information led to embarrassment abut low test scores. 
2. Use of the eligibility list by the hiring official in a prejudiced way (unconscious bias).

- A full name listed on the eligibility list could reveal gender and ethnicity, which are protected categories that cannot be collected in the application process (Giang, 2013). Although CCSF's hiring process is in compliance with the OPM's federal standards, there are potential process changes that can be implemented to better their hiring process. It is unclear if OPM publishes a public eligibility list, but CCSF is trying to solve their problem by completely de-identifying its publicly posted eligibility lists.

The questionnaire only collected responses from eight large U.S. cities therefore, it does not fully analyze all human resources hiring procedures and practices in the public sector. Although it is not certain whether publicly posting eligibility lists with personally identifying information is the sole cause for the complaints received by CCSF this analysis will help suggest whether a de-identified approach to the public posting of eligibility lists can help decrease applicant complaints, and illustrate whether de-identified practices can aid in creating a fair hiring process.

\section{Solution Development.}

This section of the study presents solutions to the problem regarding the public posting of civil service eligibility lists. With the problem CCSF was facing, the solution was to fully de-identify its civil service eligibility lists. Best practices from the questionnaire findings indicate that deidentification measures have value, especially since all cities (with the exception of CCSF) deidentify to some extent and have never received complaints regarding the posting of their eligibility lists. De-identification serves as a best practice for any agency trying to hire on a merit-based hiring system because it reduces issues such as nepotism, bias, and complaints associated with personally identifying information being released publicly. The simple measure 
of just indicating rankings, scores, and how many candidates fell into each score can aid hiring departments in deciding how many people they want to interview, and how far down the eligible list they can choose from, before judgements can be formed about a candidate. This also protects candidate privacy until it is necessary to reveal personally identifying information, later on in the hiring process.

\section{a. Educating Human Resources Professionals.}

Educating human resources professionals on the importance of impartiality and controlling nonjob related judgements during the application screening process is vital to a merit-based hiring system. The judgements of human resources professionals can affect the important public service work that is trying to be conducted. If human resources professionals can understand this, this can be the most effective factor in reducing negative externalities in the hiring process. When a person is educated on how their opinions can affect their work, it becomes easier to control them before it can cloud decision-making. Understanding these issues from the beginning will help hiring decision-makers actively reflect on their perceptions of a candidate before making judgements that should not be included in a merit-based hiring process

Based on the questionnaire results, all market cities have anti-nepotism policies and/or laws in place, and all market cities conduct bias training, which should be repeated annually. CCSF has used the complaints that they have received about nepotism-based hiring as an impetus to implement the new de-identification rule reform, and in return, it has led to applying new practices in their hiring process to reduce negative externalities. For example, prior to the deidentification implementation, hiring managers could request to see completely identifying candidate resumes. After the de-identification implementation, human resources professionals can send hiring managers "blind" resumes that do not personally identify candidates, and only 
provide information pertinent to the job qualifications. Additionally, CCSF has rolled out a new "Diversity, Equity, Inclusion, \& Implicit Bias" workshop that city employees can take in addition to its required annual online bias trainings.

\section{b. Standardizing the Hiring Process.}

Although the findings from the questionnaire produced helpful information, each market city conducts its hiring process differently. All market cities have a centralized human resources office that regulates the hiring process. This regulating office ensures that all departments follow the standards set by the city and federal government to prevent negative externalities such as nepotism and bias. This illustrates the effort that each market city takes to implement a fair hiring process. It also illustrates the importance of a standardized hiring process in a merit-based system.

Every market city (with the exception of Charlotte) use eligibility lists to fill either all of their permanent civil service positions, or just for their public safety positions. Table 6 illustrates which market cities use eligibility lists for which classifications. All market cities except for San Jose, Charlotte, and Detroit publicly post their eligibility lists. From here, the practices and processes for each market city vary. All market cities have a standardized way in which they conduct their hiring processes. The idea of de-identification has value, especially because many market cities do not post publicly and have indicated through the data that this serves the purpose of hiring with a fair and merit-based system. Market cities may either redact or include personally identifying information when distributing their eligibility lists. An important perspective to understand about whether or not city agencies de-identify their eligibility lists is how identification or de-identification methods help in conducting a fair hiring process. Do identifying eligibility lists allow human resources professionals to check their judgements before 
the hiring process is furthered? Or, do de-identifying eligibility lists permit biases to be introduced at a later stage in the hiring process?

It is important for all public agencies to research their current hiring practices to find possible gaps in their processes. Questions to consider are:

- Are all and any complaints regarding the hiring process being properly evaluated?

- Are human resources employees being reminded of the anti-nepotism laws/policies that are in place?

- What benefit is there to distributing eligibility lists with personally identifying information to hiring managers/departments before interviews are conducted?

- How can human resources professionals check their biases when screening applications or conducting other hiring processes?

Based on the practices of other market cities, CCSF is making strides in the correct direction to decrease complaints about bias and nepotism in the hiring process. Although the solutions outlined above are just recommendations that cities can choose to implement, McCormack (2016) and Jones (2012) state that employee bias awareness training, policy reminders on nepotism, and the de-identification of eligibility lists are considered to be best practices when trying to mitigate negative externalities in the hiring processes, which is CCSF's long-term goal.

\section{Solution Evaluation.}

CCSF implemented the solution of de-identifying its civil service eligibility lists as a solution to decrease the amount of complaints received. This process took time for the solution to be proposed, considered, confirmed, and then implemented. The steps CCSF took to fully deidentify its eligibility list are listed below. 
1. CCSF received the complaints regarding the public posting of eligibility lists (Callahan, 2018). The exact number of complaints were not able to be collected to present in this study.

2. CCSF held public meetings for candidates (current CCSF employees, past applicants, and future applicants) to voice their opinions on the public posting of eligibility lists ( $\mathrm{T}$. Tran, personal communication, 2019).

3. The Department of Human Resources (DHR) complied the data from the public hearings and presented the concerns to the San Francisco Civil Service Commission in January 2018 (Callahan, 2018).

4. DHR conducted a survey of large California cities and counties on their de-identification measures and $90 \%$ of those cities and counties stated they do not publicly post eligibility lists (Callahan, 2018). DHR also surveyed an additional 87 cities and counties across the U.S. and only one agency reported that is publicly posted its eligibility lists (Callahan, 2018).

5. After presenting these findings, conducting additional public and Civil Service Commission meetings, the SF Civil Service Commission passed the new rule reform to fully de-identify publicly posted eligibility lists and was implemented in October 2018 at CCSF.

The implementation of the new rule reform is relatively new and has only been in place for approximately seven months. Therefore, this study was not able to analyze CCSF's implementation experience due to time constraints and no access to previous CCSF data. Due to these limitations, this study is unable to compare the results of the new reform it to the processes 
preceding it. Future research can focus on determining whether de-identification decreases the number of complaints and/or the nature of the complaints received by CCSF.

With the data collected, it can be evaluated that CCSF is headed in the right direction with its decision to de-identify its eligibility lists. When comparing the de-identification solution to other market cities, CCSF de-identifies the most information on its eligibility lists while other market cities still include some details on their lists. CCSF is the only city that fully de-identifies its publicly posted eligibility lists. Question 14 of the questionnaire illustrated that no other market city (except for CCSF) received complaints on the public posting of its eligibility lists. With this solution in place in addition to the data collected from question 14, the study indicates that CCSF's complaints regarding the public posting of its eligibility lists will decrease - since it is following a best practices illustrated by other market cities.

\section{Phase II: Benchmarking}

Making public sector human resources professionals aware of the negative externalities that are present in the hiring process is important if a city's goals are to achieve a fair hiring process and diversity within the workplace. De-identification of the eligibility list is one way to achieve a merit-based hiring environment by removing the basis for negative externalities to occur. (McCormack, 2016). As discussed in the Literature Review, nepotism and bias in the hiring process leads to organizational problems, with long-term effects such as low employee morale, low performance, low retention, and difficult recruitment (Jones, 2012).

The questionnaire results in this study show that the majority of market cities publicly post their eligibility lists, but some market cities only partially de-identify them. The questionnaire also revealed that all of the market cities have anti-nepotism laws and/or policies in place that align with the federal standards set by the Office of Personnel Management. The 
purpose was to make an educated analysis with the support of the current literature to conclude whether de-identification is a common practice among similarly-sized American cities. Due to the limitations of the questionnaire and data collected, this study was unable to answer this question as comparison data (before and after) was not collected to show causation.

Instead, this study collected the best practices of de-identification techniques among market cities and reported on the management of civil service eligibility lists in those market cities. The evaluation is that in the market cities, de-identifying seems to be a best practice. Therefore, CCSF should use this best practice, and test whether the de-identification solution actually impacts the amount of complaints received and if nepotism and bias have been decreased in the city's hiring process. This is an area for future research that CCSF can do by collecting data on applicant complaints to determine whether this de-identification solution has impacted the hiring issues, and whether the de-identification measures meet the needs of hiring managers to obtain appropriate employees for the positions. This future research will help in better understanding the impact of de-identification and will possibly illustrate the differences of de-identification techniques used to conduct a merit-based hiring process in the public sector.

The data on de-identification best practices collected help in understanding that different cities have different processes and perspectives on what information they allow to be publicly available during the hiring process. Based on the data collected in the questionnaire, to some extent all market cities manage the information on the eligibility list, with differing objectives, such as protecting privacy based on state and federal laws. For example, four market cities State of Massachusetts, Austin, Jacksonville and Denver - publicly post their eligibility lists, giving access to hiring departments, and sometimes even the public. The Commonwealth of Massachusetts and the cities of Austin and Jacksonville redact some personally identifying 
information from their eligibility lists, but leave personally identifying information such as names, test scores, ranks, school, and degree visible. But, as stated by these market cities, none of them have ever received complaints regarding the public posting of their eligibility lists.

The City of Charlotte does not have a civil service system and therefore, does not use eligibility lists. From the data collected, their hiring process does not take any de-identification measures. Once an application is received and pre-employment tests, such as background checks and drug tests, have cleared, if a hiring manager is interested in a candidate, interviews can proceed (The City of Charlotte, 2019). No step of Charlotte's hiring process is de-identified, and the city stated that they have never received complaints. Out of all the market cities, only CCSF stated that they received complaints related to eligibility lists and bias/discrimination. Was it solely because their publicly posted eligibility lists included personally identifying information? But, per the data collected, the State of Massachusetts, Austin, Jacksonville and Denver have not received complaints even though their lists include some personally identifying information. This is an interesting detail to note, and raises an important question that will require further research to answer: are other cities not receiving complaints because of their robust hiring processes and practices, or is the City and County of San Francisco taking high-level precautions to cut discrimination from their hiring process because of a different level of community sensitivity to past hiring practices? 


\section{CONCLUSION}

The market cities selected for this study possess many differences from the benchmark agency, which is the City and County of San Francisco (CCSF). The methodology used for the analysis of this study involved finding the various de-identification methods used by the market cities in comparison to the CCSF. As discussed in the findings and analysis, CCSF has taken a completely de-identified approach to managing their eligibility lists in order to combat the complaints that they have received regarding the public posting of their eligibility lists. Deidentification of the list at all levels of publication and use was selected because CCSF wants to reduce the amount of discrimination that can be present in the hiring process when personally identifying information is available for hiring decision-makers to access.

After reviewing CCSF's eligibility list management practices and comparing them to the practices of other market cities, it appears that de-identifying eligibility lists has value - since all cities de-identify their eligibility lists to some extent. Per the data collected and the research presented in the Literature Review, de-identification measures are meant to enhance the fair management of public sector eligibility lists.

Based on the studies conducted by Bertrand and Mullainathan (2003), Carlsson and Rooth (2008), and Goldin and Rouse (1997) all cities that would like to maintain a merit-based hiring process should consider implementing de-identification practices into aspects of their hiring processes - this helps to maintain a merit-based hiring process. For example, cities can conduct "blind" application screenings or interviews in order to make hiring decisions with the least amount of bias or discrimination. This idea is supported by Rinne (2018), who stated that deidentified techniques help to control biases and judgements that affect hiring decisions. These techniques will ideally lead to more conscious public sector hiring practices. 



\section{REFERENCE LIST}

Bardach, E., \& Patashnik, E. M. (2015). A practical guide for policy analysis: The eightfold path to more effective problem solving. Los Angeles, CA: CQ Press/SAGE.

Beattie, G., Johnson, P. (2011). Possible unconscious bias in recruitment and promotion and the need to promote equality. Perspectives: Policy and Practice in Higher Education, 16(1), 7-13. https://doi.org/10.1080/13603108.2011.611833.

Bertrand, M. \& Mullainathan, S. (2003). Are Emily and Greg more employable than Lakisha and Jamal? A field experiment on labor market discrimination. National Bureau on Economic Research. Cambridge, MA. https://www.nber.org/papers/w9873.pdf.

California Department of Fair Employment and Housing. (2019). Employees and job applicants are protected from bias. Retrieved from https://www.dfeh.ca.gov/employment/.

California Legislative Information. (2019). Division 3: Employment relations. Retrieved from http://leginfo.legislature.ca.gov/faces/codes_displayexpandedbranch.xhtml?tocCode=LA $\mathrm{B} \&$ division $=3 . \&$ title $=\&$ part $=\&$ chapter $=\&$ article $=$

Callahan, M. (2018). Proposed changes to civil service commission rules: 102, definitions; 110, examination announcements and applicants; Rule 111A, position-based testing; Rule 112, eligible lists; and Rule 113, certification of eligibles to provide for expanded applicant confidentiality to support de-identification of applicant information and the proposed implementation of de- identification actions in the departmental post-referral selection process. City and County of San Francisco. Department of Human Resources. San Francisco, CA.

Carlsson, M. \& Rooth D. O. (2008). Is it your foreign name or foreign qualifications? An experimental study of ethnic discrimination in hiring. The Institute for the Study of Labor (IZA). Bonn, Germany. http://ftp.iza.org/dp3810.pdf.

Chieppo, C. (2013). The civil service systems governments need for the modern era. Retrieved from https://www.governing.com/blogs/bfc/col-civil-service-public-workforceupdate-modern-era.html.

City and County of San Francisco: Civil Service Commission. (2018). October 1, 2018 minutes. Retrieved from https://sfgov.org/civilservice/meeting/civil-service-commissionoctober-1-2018-minutes.

City and County of San Francisco: Department of Human Resources. (2018). City and county of San Francisco: Department of human resources eligible list. Retrieved from https://sfdhr.org/sites/default/files/documents/Eligible-Lists/2018/7371-M00182-tueamd.pdf.

City and County of San Francisco: Civil Service Commission. (2018). Rule 112 eligible lists. 
Retrieved from https://sfgov.org/civilservice/rule-112-eligible-lists.

City and County of San Francisco: Department of Human Resources. (2018). Exam information. Retrieved from https://sfdhr.org/exam-information.

City and County of San Francisco: Department of Human Resources. (2018). Examination results. Retrieved from https://sfdhr.org/examination-results.

City and County of San Francisco: Department of Human Resources. (2018). How to apply for a position. Retrieved from https://sfdhr.org/HOW-APPLY-POSITION.

City and County of San Francisco: Department of Human Resources. (2018). Information about the hiring process. Retrieved from https://sfdhr.org/information-about-hiringprocess\#eligiblelists.

City of Austin. (2014). Municipal civil service rules of the city of Austin. Retrieved from http://www.austintexas.gov/sites/default/files/files/Communications/Council_Approved MCS_Rules_6_26_14.pdf\#page=11.

City of Jacksonville, Florida. (2016). City of Jacksonville, Florida civil service and personnel rules and regulations. Retrieved from http://www.coj.net/getattachment/Departments/ Employee-Services/Civil-Service-and-Personnel-Rules-and-Regulations/Civil-ServiceRules-September-2016-(1).pdf.aspx.

Civil Service Commission City and County of San Francisco. (2016). Policy on family and romantic relationships at work. Memorandum: CSC No. 2016-04. Retrieved from https://sfgov.org/civilservice/sites/default/files/Notice\%20of\%20PostingPolicy\%20on \%2 0Family\%20and\%20Romantic\%20Relationships\%20at\%20Work.pdf.

Civil Service Commission City and County of San Francisco. (2017). Policy on family and romantic relationships at work. Memorandum: CSC No. 2017-01. Retrieved from https://sfgov.org/civilservice/sites/default/files/CSC\%20Memo\%20and\%20Policy\%20on \%20Family\%20and\%20Romantic\%20Relationships\%20at\%20Work.pdf.

Cozzetto, D. A., \& Pedeliski, T. B. (1997). Privacy and the workplace: Technology and public employment. Public Personnel Management. http://libaccess.sjlibrary.org/login?url $=$ http: $/ /$ search.ebscohost.com $/ \operatorname{login}$. aspx $?$ direct $=$ true $\& \mathrm{db}=\mathrm{bth} \& \mathrm{AN}=56312 \&$ site $=$ bsilive \&scope $=$ site.

Davids, C., Boyce G. (2008). Conflict of interest in the public sector. Macquarie University, Victoria Ombudsman. https://www.ombudsman.vic.gov.au/getattachment/f6ba83982e7b-41f6-bbfd-bed87f0bcfac/publications/parliamentary-reports/conflict-of-interest-inthe-public-sector.aspx.

Electronic Code of Government Regulations. (2019). Affirmative action and nondiscrimination obligations. Retrieved from https://www.ecfr.gov/cgi-bin/text-idx?SID=c27f38f259759b 
7bd9505921\&mc=true\&node=pt41.1.60_6741\&rgn=div5.

FEDWeek. (2018). RIP, rule of three. Retrieved from https://www.fedweek.com/fedweek/riprule-of-three/.

Federal News Network. (2014). Should we bring back the "Rule of three"? Retrieved from https://federalnewsnetwork.com/commentary/2014/10/should-we-bring-back-the-rule-ofthree/.

Giang, V. (2013). 11 common interview questions that are actually illegal. Retrieved from https://www.businessinsider.com/11-illegal-interview-questions-2013-7.

Goldin, C. \& Rouse, C. (1997). Orchestrating impartiality: The impact of "blind" auditions on female musicians. National Bureau on Economic Research. Cambridge, MA. https://www.nber.org/papers/w5903.pdf.

Government of Northwest Territories. (2018). 0102b - Eligibility lists. Canada. Retrieved from https://my.hr.gov.nt.ca/human-resource-manual/0100-hiringprocess/0102b-eligibility-lists.

Holroyd, J., Scaife, R., Stafford, T. (2017). What is implicit bias? Philosophy Compass. 12(10), 31-37. https://doi.org/10.1111/phc3.12437.

ICMA, The International City/County Management Association. (2008). Forms of local government. Retrieved from https://icma.org/documents/forms-local-governmentStructure.

ICMA, The International City/County Management Association. (2018). Council-manager form of government. Retrieved from https://icma.org/sites/default/files/18027\%20Council\%20Manager\%20FOG\%20Brochure_final\%2010-16-17.pdf

International Labour Organization. (2017). Breaking barriers: Unconscious gender bias in the workplace. The Bureau for Employer's Activities. https://www.ilo.org/wcmsp5/groups/ public/---ed_dialogue/---act_emp/documents/publication/wcms_601276.pdf.

Jones, R. G. (2012). Nepotism in Organizations. New York, NY. Routledge: Taylor \& Francis Group, LLC.

McCormack, H. (2016). The real effects of unconscious bias in the workplace. UNC KenanFlagler Business School, Executive Development. https://www.kenanflagler.unc.edu/ /media/Files/documents/executive-development/unc-white-paper-thereal-effects-of-unconscious-bias-in-the-workplace-Final.

McDonald Jr., J.J. (2017). Employment at will: What it really means in California. Society for Human Resource Management. https://www.shrm.org/resourcesandtools/legal-andcompliance/state-and-local-updates/pages/employment-at-will-in-california.aspx. 
McKay, D.R. (2018). Civil service employment: Government jobs in the U.S. Retrieved from https://www.thebalancecareers.com/civil-service-employment-525874.

Mertz, N.T. (2011). Chapter 3: Women of color faculty: recruitment, hiring, and retention. In Gaëtane Jean-Marie, Brenda Lloyd-Jones (Eds.), Women of Color in Higher Education: Changing Directions and New Perspectives (41-71). United Kingdom: Emerald Group Publishing.

Moss-Racusin, C. A., Dovidio, J. F., Brescoll, V. L., Graham, M. J., \& Handelsman, J. (2012). Science faculty's subtle gender biases favor male students. Proceedings of the National Academy of Sciences. 109(41), 16474-16479.

Moule, J. (2009). Understanding unconscious bias and unintentional racism. Phi Delta Kappa. 90(5), 320-326. https://doi.org/10.1177/003172170909000504.

National League of Cities. (2019). Forms of municipal government. Retrieved from https://www.nlc.org/forms-of-municipal-government.

New York City Citywide Administrative Services. (2018). The civil service system. Retrieved from http://www.nyc.gov/html/dcas/html/work/civilservice.shtml.

Office of Personnel Management. (2019). Employee relations. Retrieved from https://www.opm.gov/policy-data-oversight/employee-relations/.

Office of Personnel Management. (2019). Step 8: Evaluate applications. Retrieved from https://www.opm.gov/policy-data-oversight/human-capital-management/hiringreform/hiring-process-analysis-tool/evaluate-applications/.

Office of Personnel Management. (2019). Step 9: Issue certificate and notify eligibles. Retrieved from https://www.opm.gov/policy-data-oversight/human-capitalmanagement/hiring-reform/hiring-process-analysis-tool/issue-certificate-and-notifyeligibles/.

Office of Personnel Management. (2019). Step 10: Review applications, schedule and conduct interviews, check references, make selection and return certificate. Retrieved from https://www.opm.gov/policy-data-oversight/human-capital-management/hiringreform/hiring-process-analysis-tool/review-applications-schedule-and-conductinterviews-check-references-make-selection-and-return-certificate/.

Office of Personnel Management. (2019). Veterans services: Vet guide. Retrieved from https://www.opm.gov/policy-data-oversight/veterans-services/vet-guide-for-hrprofessionals/.

Padgett, M. Y., \& Morris, K. A. (2005). Keeping it "All in the family:” Does nepotism in the hiring process really benefit the beneficiary? Journal of Leadership \& Organizational 
Studies. 11(2), 34-45. https://doi.org/10.1177/107179190501100205.

Rinne, U. (2018). Anonymous job applications and hiring discrimination. IZA World of Labor: 48. doi: 10.15185/izawol.48.v2. https://wol.iza.org/articles/anonymous-job-applications -and-hiring-discrimination/long.

Roberts, R. N., \& Doss Jr., M. T. (1991). The constitutional privacy rights of public employees. International Journal of Public Administration. http://libaccess.sjlibrary.org/ login?url=http://search.ebscohost.com/login.aspx?direct=true \&db=poh\&AN=12143388\& site $=$ ehost-live \&scope $=$ site.

Rosenbloom, D. H., Kravchuk, R. S., \& Clerkin, R. M. (2014). Public administration: Understanding management, politics, and law in the public sector. 8th edition, Boston: McGraw Hill.

Ross, H. (2008). Strategies for addressing unconscious bias in the workplace: Exploring unconscious bias. Diversity Best Practices. 2(5), 1-3. http://www.dphu.org/uploads/ attachements/books/books_5073_0.pdf.

San Francisco Campaign and Governmental Conduct Code. (2018). Article III: Conduct of government officials and employees. Retrieved from http://ibrary.amlegal.com/nxt/ gateway.dll/California/campaign/campaignandgovernmentalconductcode? $\mathrm{f}=$ templates $\$ \mathrm{fn}$ $=$ default.htm $\$ 3.0 \$$ vid=amlegal:sanfrancisco_ca $\$$ sync $=1$.

Schmitt, M. \& Martin, K. (2018). Hiring and employment in Philadelphia city government: An examination of the structure, processes, and challenges with the current system. The Pew Charitable Trusts. https://www.pewtrusts.org/-/media/assets/2018/06/hiring_and_emp loyment_in_philadelphia_city_government_report.pdf.

Shattuck, C.A. (1989). The tort of negligent hiring and the use of selection devices: The employee's right of privacy and the employer's need to know. Berkeley Journal of Employment \& Labor Law. https://doi.org/10.15779/Z38562V.

Spearritt, K. (2018). Building inclusive workplaces to optimise diversity of talent and ideas. White Paper. https://static1.squarespace.com/static/5768bad146c3c 4f67570dcf6/t/59d59cf5cf81e0daf7b47422/1507171657530/White+Paper+Final.pdf.

State of California Department of Justice. (2019). Workplace privacy: Privacy on the job search. Retrieved from https://oag.ca.gov/privacy/workplace-privacy.

Sundell, A. (2014). Are formal civil service examinations the most meritocratic way to recruit civil servants? Not in all countries. Public Administration. 92(2), 440-457. http://web.a.ebscohost.com.libaccess.sjlibrary.org/ehost/detail/detail? vid=2\&sid=90d123 cc-2a3e-4d5-a705-1d89a6817529\%40sdcvsessmgr06\&bdata=JnNpdGU9ZWhvc3QtbG1 2ZSZzY29wZT1zaXRl\#AN=96443727\&db=poh. 
Sylvia, R., \& Sylvia, K. (2012). Program planning and evaluation for the public manager. Long Grove, IL: Waveland Press, Inc.

Tetlock, P.E., Mitchell, G. (2009). Implicit bias and accountability systems: What must organizations do to prevent discrimination? Research in Organizational Behavior. 10(29), 3-38. https://doi.org/10.1016/j.riob.2009.10.002.

U.S. Department of Labor. (2019) Affirmative action. Retrieved from https://www.dol.gov /general/topic/hiring/affirmativeact.

U.S. Merit Systems and Protection Board. (2016). Preventing nepotism in the federal civil service. Retrieved from https://www.mspb.gov/mspbsearch/viewdocs.aspx?doc number $=1315054 \&$ version $=1320272 \&$ application $=$ ACROBAT . 


\section{APPENDIX}

De-Identification Questionnaire:

1. What city government are you currently an employee at?

San Jose, CA

Austin, TX

Jacksonville, FL

San Francisco, CA

Charlotte, NC

Seattle, WA

Detroit, MI

Denver, $\mathrm{CO}$

Other (please describe below)

2. What city department are you currently working for? (i.e. Department of Human Resources, Department of Public Health, Department of Public Works, Department of Transportation, Department of Parks \& Recreation, etc.) Please enter below.

3. What is your role in your department or title of your position?

Department Head

Hiring Manager

Human Resources Analyst

Human Resources Technician

Human Resources Generalist

Administrative

Other (please describe below)

4. Does your city have a centralized human resources office that regulates HR activities for all city departments?

Yes

No

Our agency uses an outside vendor/contractor

4A. If "no", does your department create \& manage the rules and policies for its own recruitment and hiring?

Yes
No

5. Does your agency use eligibility lists when filling any permanent civil service positions?

(NOTE: an eligibility list may also be referred to as a "referral" list or "certification" list by varying city agencies/departments)

Yes

No 
5A. If "yes", based on your professional knowledge, which classifications use eligibility lists? (select all that apply)

All job-classifications

Sworn classifications (i.e. police and fire departments)

Management classifications (i.e. directors, managers, and supervisors)

Non-Management classifications (i.e. clerical, technical, labor, administrative, analysts, dispatchers, librarians, accountants, planners, operations specialists, and others) Other (please describe below)

6. Are the eligibility lists publicly posted?

Yes

No

6A. If "yes", Where are the eligibility lists posted and/or distributed to? (select all that apply)

Our agency does not post eligibility lists publicly

Online on agency website

Physical copy mailed to candidates

Electronic copy e-mailed to candidates

Hard copy posted at the agency office

Hard copies are available for the public to pick-up, print, and/or copy

Eligibility lists are distributed to departments that need to fill positions

Other (please describe below)

7. Are eligibility lists posted/distributed with any personally identifying information about the candidate? (i.e first and/or last name, gender, race, etc.)?

Yes

No

Our agency does not list eligibility lists publicly

8. Does your agency redact personal identifying information (i.e. names) before posting/distributing eligibility lists publicly?

Yes

No

Our agency does not list eligibility lists publicly

9. What type of personally identifying information is included on the eligibility lists? (select all that apply)

First Name

Middle Name

Last Name

Test Score

Position on the eligibility list

Coded identifier

Address 
Phone Number

School

Degree

Gender/Sex

Race/Ethnicity

Citizenship Status

Marital Status

Veteran Status

Other personal identifying information (please describe below)

10. If names are not used on the eligibility list, is the candidate assigned a coded identifier on the eligibility list?

Yes

No

Our agency uses names on the eligibility lists

11. If your agency uses coded identifiers on the eligibility list, how are coded identifiers assigned?

My agency does not use coded identifiers

Letters

Numbers

Alphanumeric Combination

Other (please describe below)

12. How are candidates informed about their scores and ranks on an eligibility list? (select all that apply)

Phone Call

E-mail

Letter

Other (please describe below)

13. Is your agency required by any law, legal policies, and/or rules to redact personally identifying information on eligibility lists?

Yes

No

13A. If "yes", which of these laws, legal policies, or rules require you to redact personally identifying information from eligibility lists? (select all that apply) Civil Service Commission Rule(s)

State $\operatorname{Law}(\mathrm{s})$

City Ordinance(s)

Department Rule(s)

Department Process(es)

Historic Practice 
14. Has your agency received complaints, appeals, or protests about the posting of eligibility lists? Yes No

14A. If "yes", which of the following complaints has your agency received? (select all that apply)

Our agency has never received complaints regarding eligibility lists Candidate embarrassment about applying for public job Candidate concern about current employer seeing name on list Candidate embarrassment about score Candidate embarrassment about position on list Candidate concern that personal identifiers could lead to bias in hiring

Candidate concern about discrimination Candidate concern on nepotistic hiring decision(s) Other (please describe below)

15. Are you required to redact any personally identifying information (i.e. names) before distributing eligibility lists to the individual(s) and/or team making the hiring decision? Yes No Individual(s) and/or team making the hiring decision never see a redacted OR unredacted eligibility list

16. When are the individual(s) and/or team making the hiring decision disclosed with the personally identifying information about the candidates that have moved further on in the hiring process? (select all that apply)

When screening applications

When the eligibility list is publicly posted

When the eligibility list is requested to fill a position(s)

When candidates are being selected for interviews

When interviews are being scheduled

When interviews take place

Never

Other (please describe below)

17. What type of eligibility list is provided to the individual(s) and/or team making the hiring decision?

Redacted (i.e. does not include personally identifying information)

$17 \mathrm{~A}$. What is removed?

First Name 


Middle Name
Last Name
Test Score
Position on the eligibility list
Coded identifier
Address
Phone Number
School
Degree
Gender/Sex
Race/Ethnicity
Citizenship Status
Marital Status
Veteran Status
Other (please describe below)

Un-redacted (i.e. includes personal identifying information)

17B. What is listed?

First Name
Middle Name
Last Name
Test Score
Position on the eligibility list
Coded identifier
Address
Phone Number
School
Degree
Gender/Sex
Race/Ethnicity
Citizenship Status
Marital Status
Veteran Status
Other (please describe below)

18. Based on your professional knowledge, do other departments within your agency redact eligibility lists when using internal selection processes?

Yes

No

We are not allowed to use our own internal selection processes

19. Based on your professional knowledge, does your city have anti-nepotism laws or policies in place?

Yes 
No

20. Based on your professional knowledge, does your agency provide bias training to human resources professionals across all city departments? Yes

No 